\title{
THE REALITY AND EXPECTATION OF THERMAL INSULATION OF HOUSING BUILDINGS: THE CASE OF RIYADH CITY IN THE KINGDOM OF SAUDI ARABIA
}

\author{
Dr. Ibrahim Ben Rashed Ben Saad Al-Jowair \\ Assistant Professor of Housing Design and Architectural Practice, Department \\ of Architectural and Building Sciences, Faculty of Architectural and Planning, \\ King Saoud University, P.O.Box 75495 - Riyadh 11578- Saudi Arabia, \\ Tel. 4677082 - Fax. 4675775 \\ Email: irjowair@ksu.edu.sa
}

(Received May 17, 2006 Accepted July 27, 2006)

\begin{abstract}
Being the largest in land occupation and population, City of Riyadh has the largest number of buildings in the Arab Gulf Countries. The assumption among practitioners that building external walls with insulated cement or adobe block will provide thermal insulation is wide spread. Any thermal insulation to any building should include all external horizontal and vertical structural elements beside windows and doors regardless of the used material or method of construction.
\end{abstract}

The aim of the study is to represent the reality of thermal insulation to the city's housing buildings thorough the clarification of the practitioners' and clients' and related agencies' understanding of building thermal insulation. All necessary data were collected by using sample of housing units selected randomly as well as open-ended interviews to randomly selected practitioners, clients and engineers in the licensing department at the Municipality of Riyadh and the Saudi Electricity Company.

Before mandatory application of housing building thermal insulation, it is necessary to implement the following regulations:

1- No issuing of building permit to new housing buildings which its construction drawings do not have a full thermal insulation.

2- The introduction of mandatory site supervision by the designer to insure the full and accurate implementation of thermal insulation.

3- Water and electricity services should be denied to any housing units does not have a written report signed by the Municipality of Riyadh and the consultant office indicating the full implementation of thermal insulation.

The Municipality of Riyadh with its current authority can not insure the full implementation of thermal insulation in housing units without the starting the use of Building Occupancy Permits as a toll to insure the inclusion of full thermal insulation in new and old buildings. 


\title{
العزل الحراري للمباني السكنية بين الواقع والمأمول: حالة دراسية لمدينة الرياض بالمملكة العربية السعودية الماية حالية
}

\author{
د. إبراهيم بن راشد بن سعد الجوير \\ أستاذ تصاميم الإسكان وممارسة مهنة العمارة المساعد بلدير
}

\begin{abstract}
الملخص تصن
تعد مدينة الرياض من أكبر المدن مساحة وسكاناً بين دول مجلس التعاون الخليجي وبالتالي الأكثر

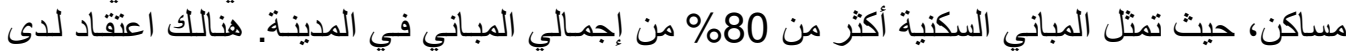

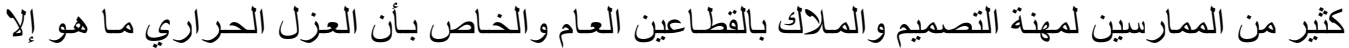
بناء الحوائط الخارجية بالطوب الأسمنتي أو الطوب الأحمر المعزول.
\end{abstract}

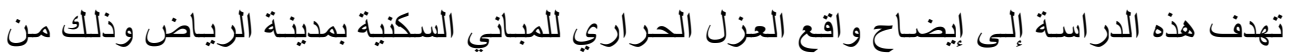

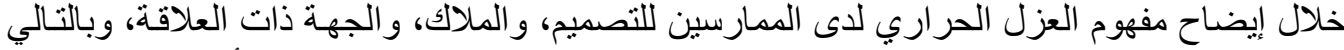

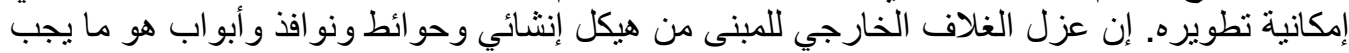
عمله بغض النظر عن المو اد المستخدمة أو الطريقة.

تم جمع المعلومات لهذه الدر اسة عن طريق رفع ميداني لعينـة مختارة عشو ائياً لمسـاكن في إحياء

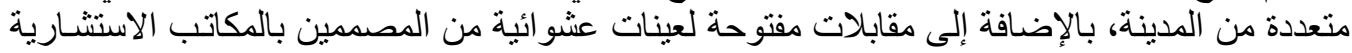

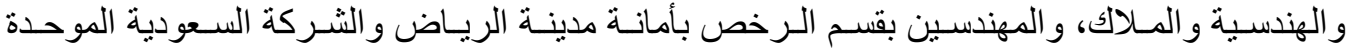

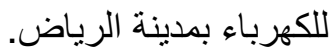

لضمان البدايـة الصحيحة في تطبيق العزل الحراري للمبـاني السكنية بمدينـة الريـاض لا بـد من إصدار نظام يشمل الخطو ات التنفيذية الثناث التالية:

1- عدم اعتماد أي مخطط لأي مبنى سكني لا يتوفر بـه العزل الحراري لكامل أجزاء الغلاف الزارجي للمبنىً.

2- إلزام المكتب المصمم بتقيم ما يفيد بقيام المالك بتنفيذ العزل الحر اري كمـا ورد بالمخططسات

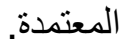

3- عدم توصيل الخدمات العامة من ماء وكهرباء و غير ها لأي مبنى سكني لا يقدم مالكه تقريراً

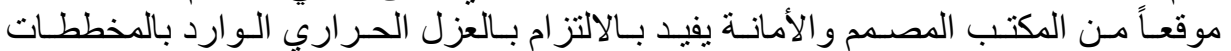

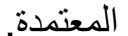

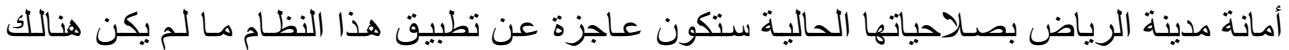

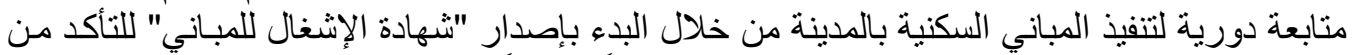
وجود العزل الحراري لكامل أجزاء المبنى الخارجية أفقياً ور أسياً للمباني الحديثة.

مقدمة

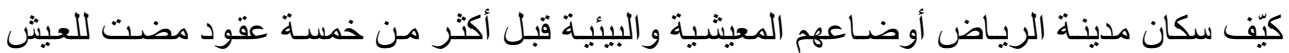

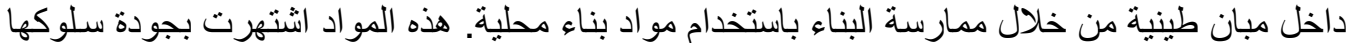

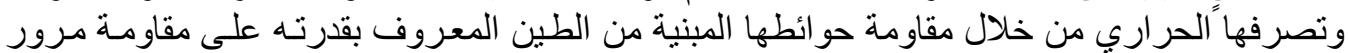

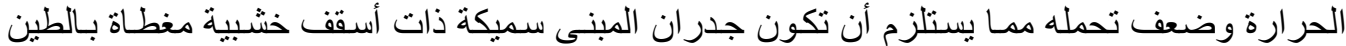

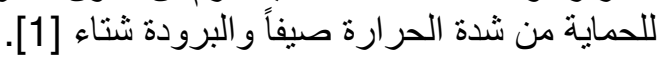




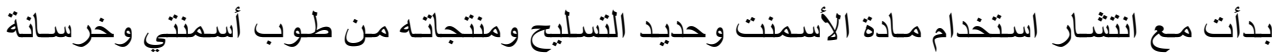

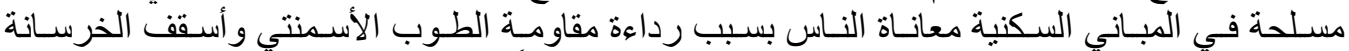

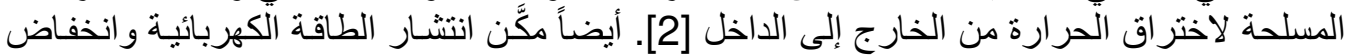

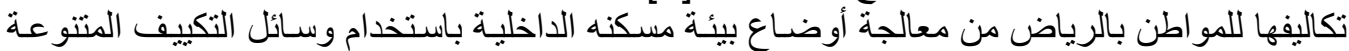

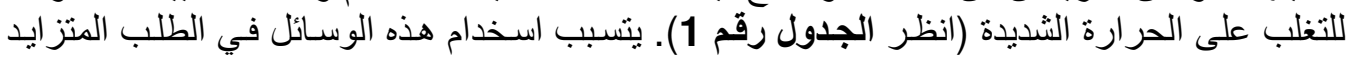

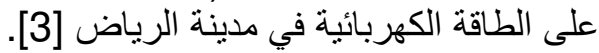

الجدول رقم (1): درجات الحرارة الكبرى والصغرى ومعدل الرطوبة النسبية لمدينة الرياض للعام 2004م.

\begin{tabular}{|c|c|c|c|c|c|c|c|c|c|c|c|c|}
\hline 荬 & 多 & 牙 & 沀 & 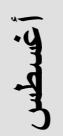 & 3; & 子' & $\frac{3}{3}$ & $\overline{3}$ & $\frac{3}{3}$ & $\frac{9}{1 ;}$ & $\frac{7}{13}$ & عنصر المناخ \\
\hline 28 & 32 & 39 & 44 & 47 & 47 & 47 & 44 & 40 & 36 & 33 & 29 & الكبرى الحرارة \\
\hline 9 & 13 & 18 & 22 & 27 & 27 & 27 & 20 & 19 & 8 & 7 & 4 & الصغة الحرارة \\
\hline 59 & 35 & 19 & 14 & 13 & 11 & 11 & 16 & 26 & 27 & 36 & 41 & النسبية الرطوبة \\
\hline
\end{tabular}

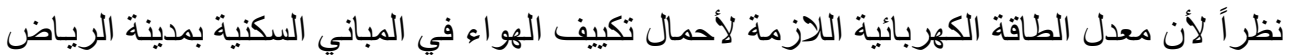

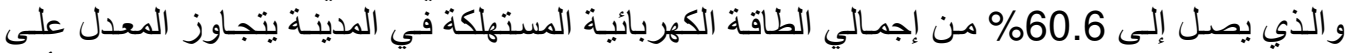

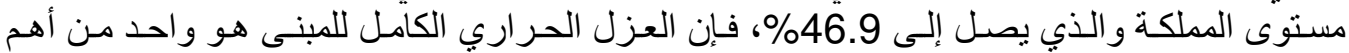

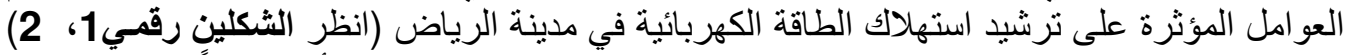

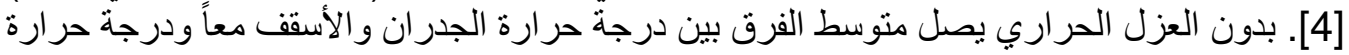

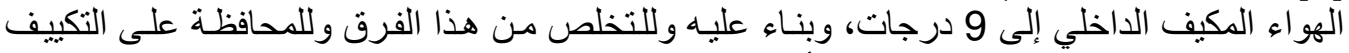

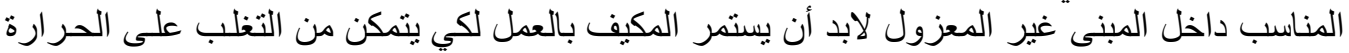

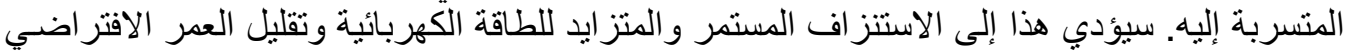

للمكيف [5].

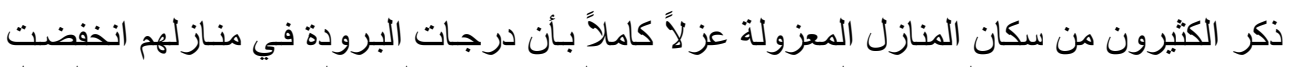

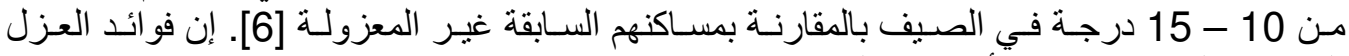

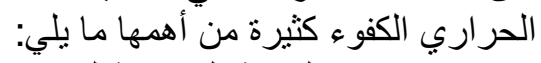

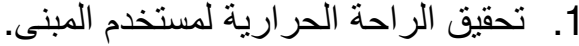

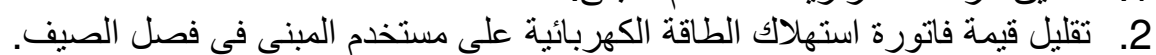

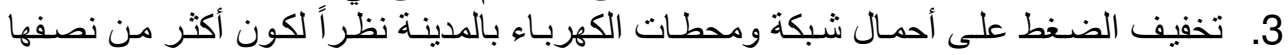
مسخر لتشغيل أجهزة ووسائل التكييف في فصل فهل الصنيف الصيف.

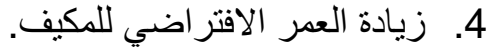
5. ترشيد استهلاك الطاقة على مستوى المملكة. 


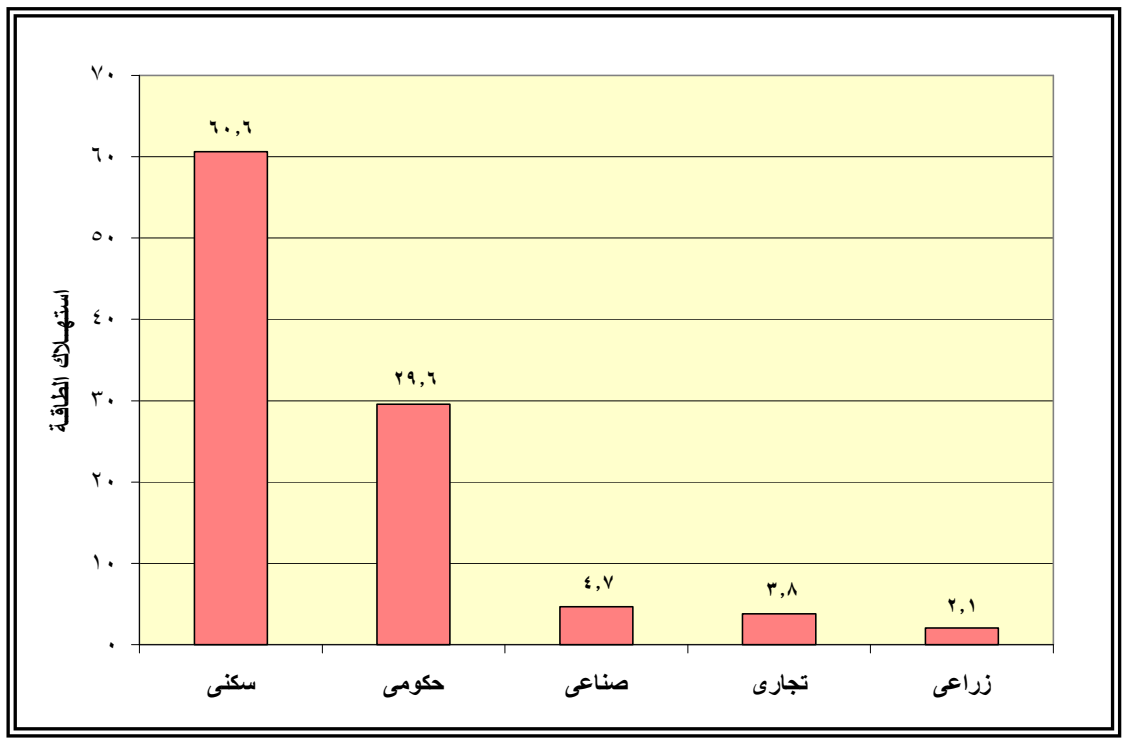

الشكل رقم 1: مقارنة لاستهلاك الطاقة الكهربائية بين المباني السكنية ومختلف المباني في مدينة الرياض.

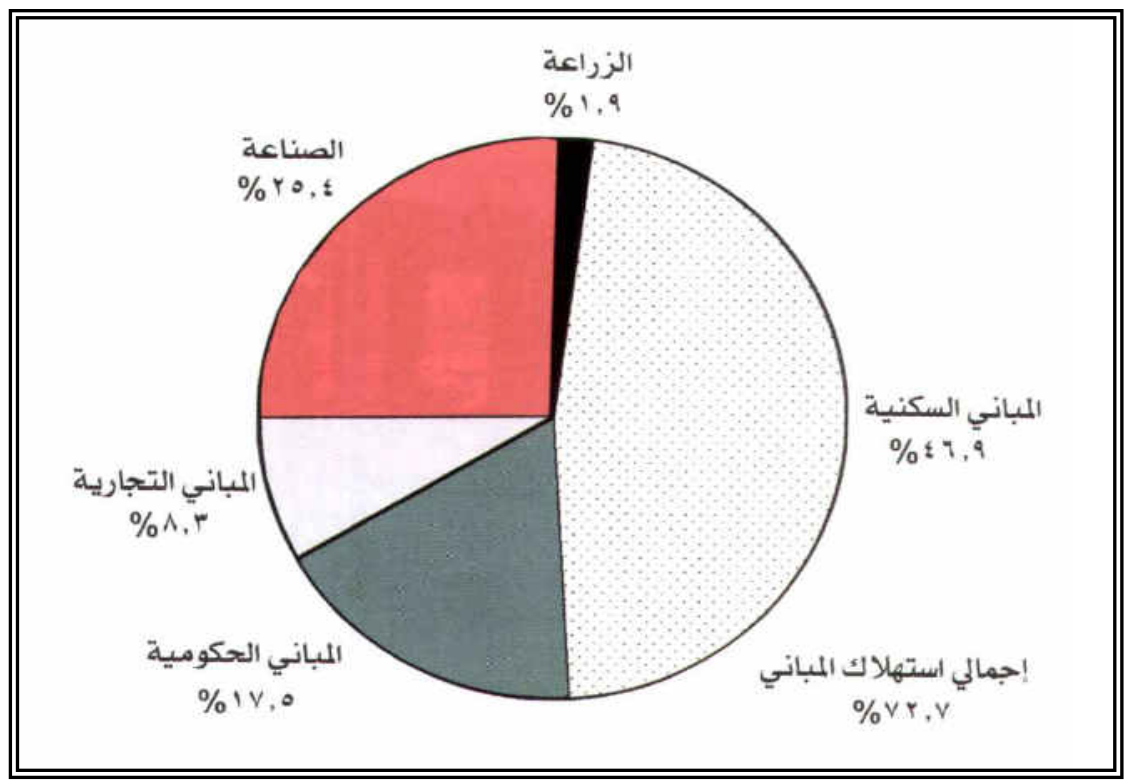

الثكل رقم 2: استهلاك الطاقة الكهربائية في مختلف القطاعات في المملكة العربية السعودية (المرجع: مجلة تقنية البناء).

أهداف البحث

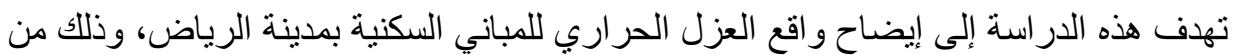

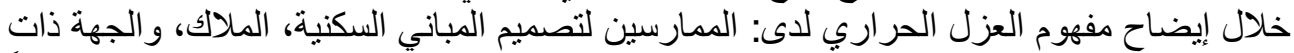

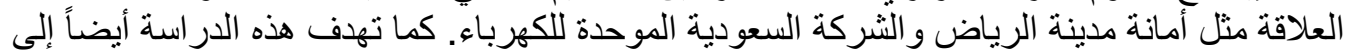

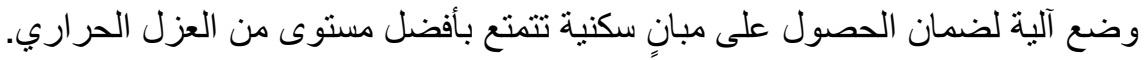


أعنمد البحث على ما ليلي:

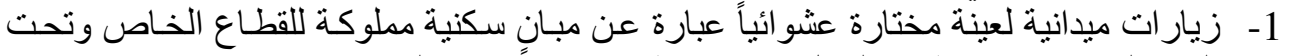

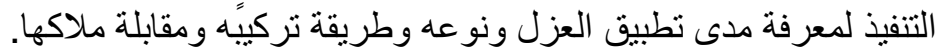

2- مقابلات مفتوحة لعينات عشو ائية من المصممين بالمكاتب الهندسية و الاستشارية.

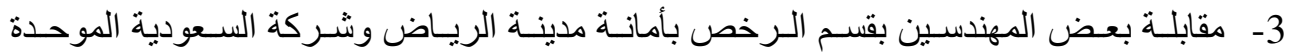

للكهرباء بمدينة الرياض. بعن.

مراجعة الدراسات السابقة

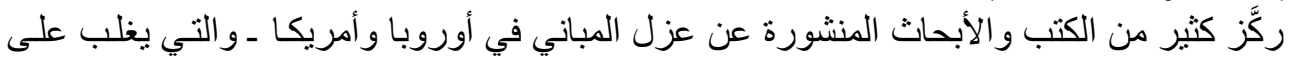

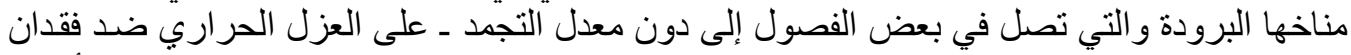

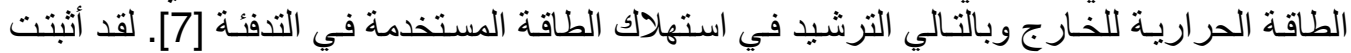

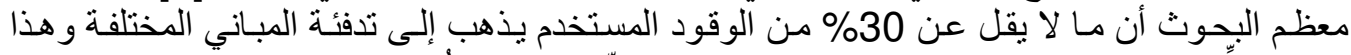

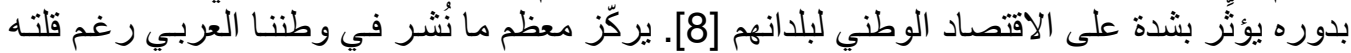

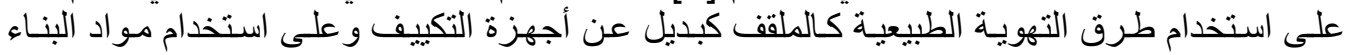

المحلية مثل الطين في المباني لتميز ها في مقاومة توصيل الحرارة كبيل كبديل لمواد العزل العزل الحديثة [9].

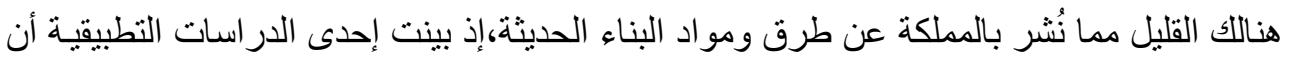

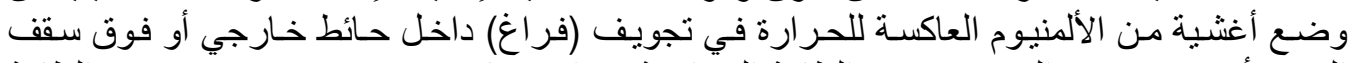

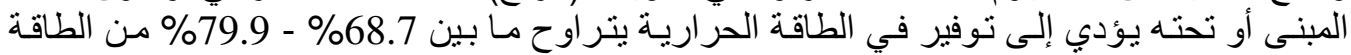

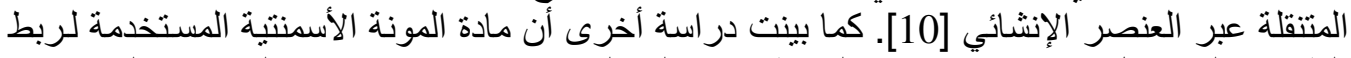

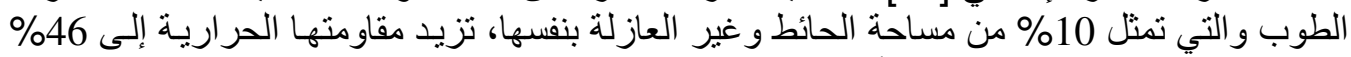
بعد إضافة مادة عازلة إلى المونة الأسمنتية [11].

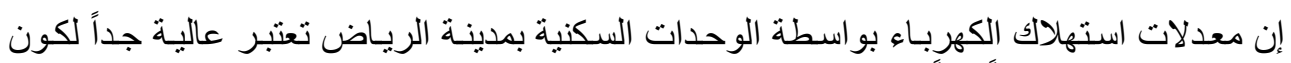

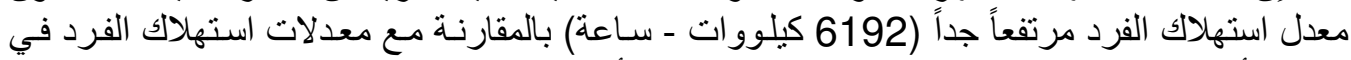

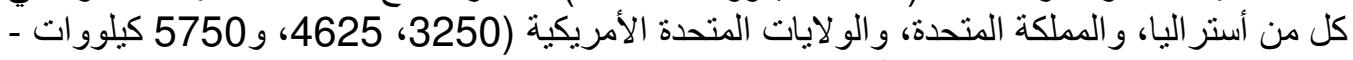

ساعة على التوالي) (انظر الثكل رقم 3) [12].

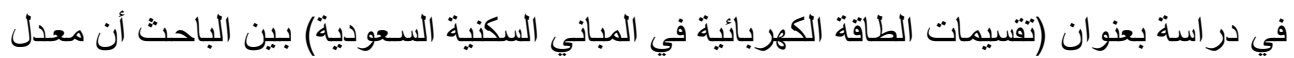

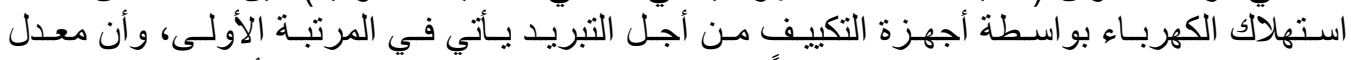

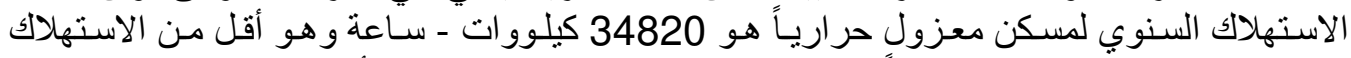

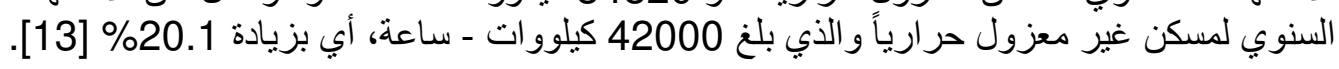

الوضع الراهن

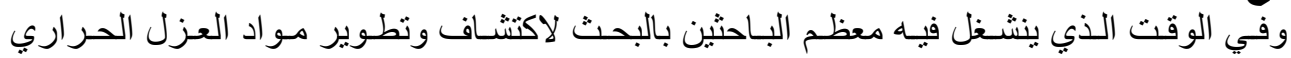

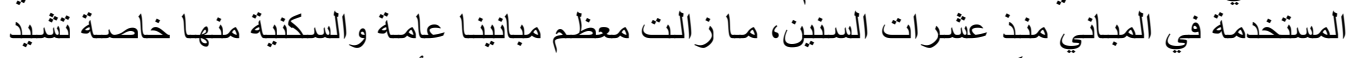

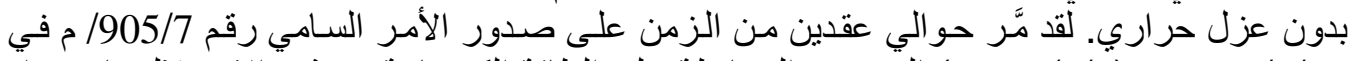

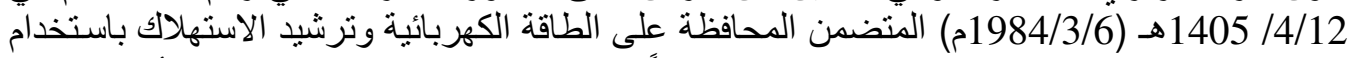

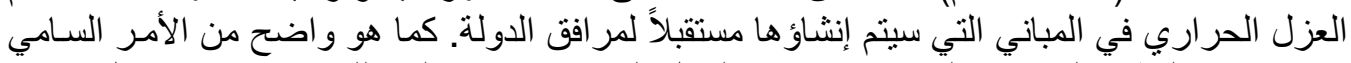

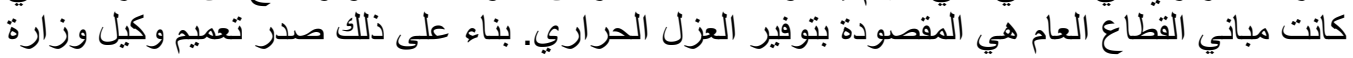

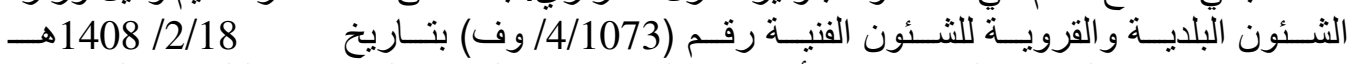

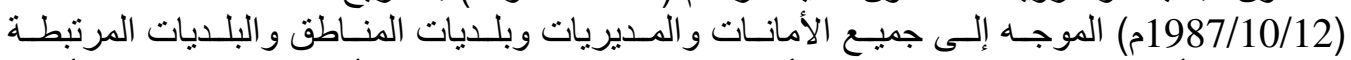

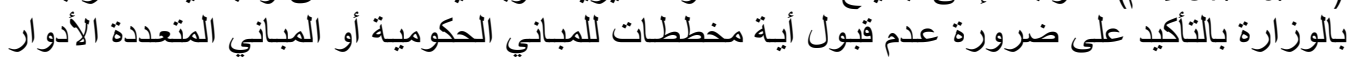


التجارية و السكنية و عدم منح رخصة البناء لها ما لم يوضح بها نو التوع ومو اصفات مو اد العزل الحر اري.

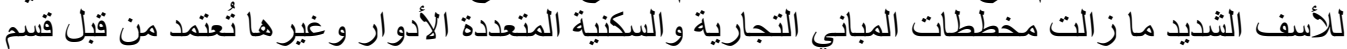

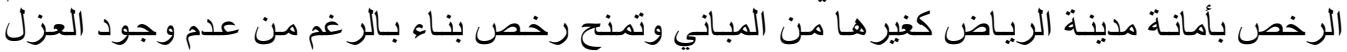

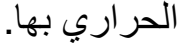

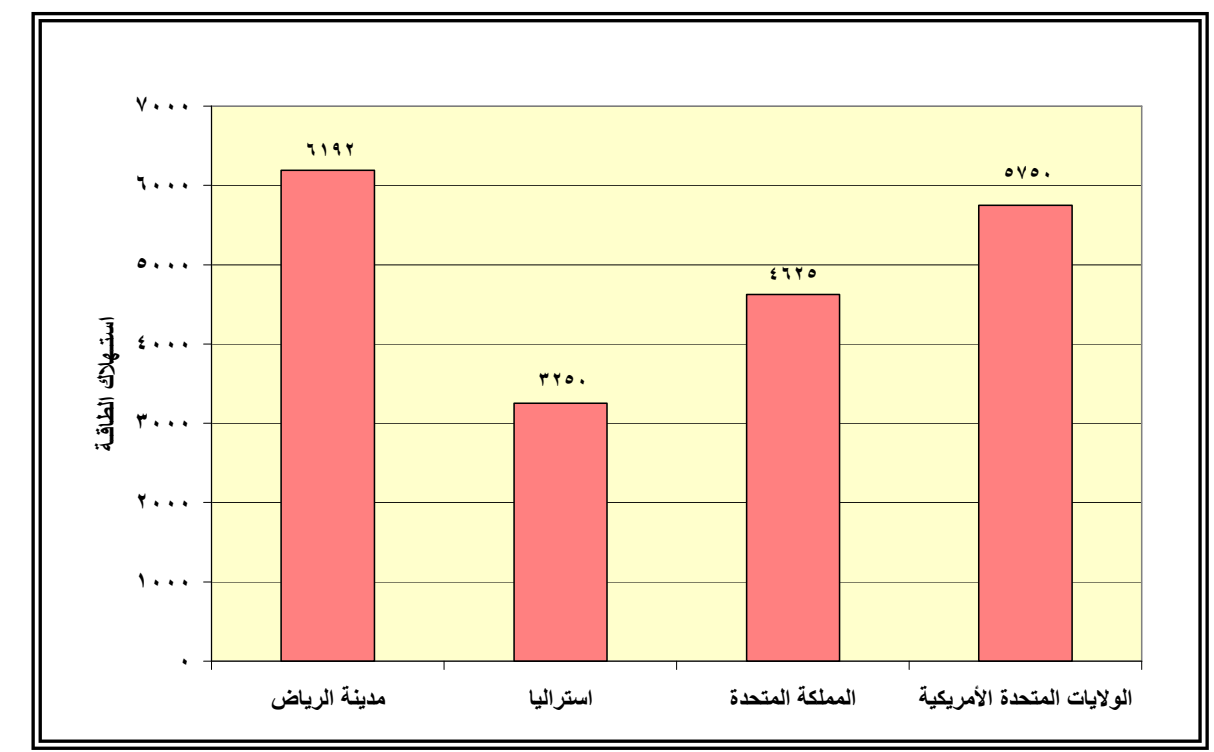

الثكل رقم 3: مقارنة بين استهلاك الفرد للطاقة الكهربائية في مدينة الرياض و أستر اليا و المملكة المتحدة والو لايات المتحدة الأمريكية.

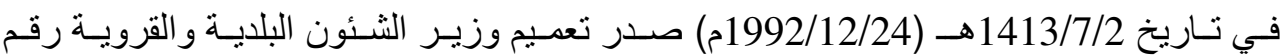

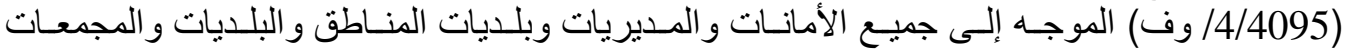

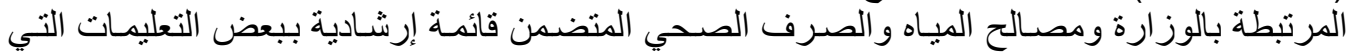

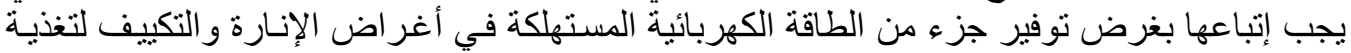

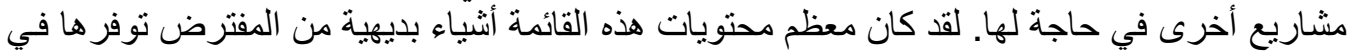

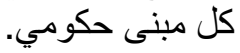

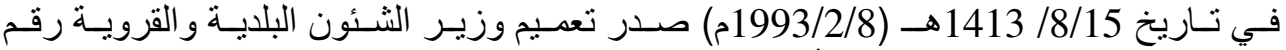

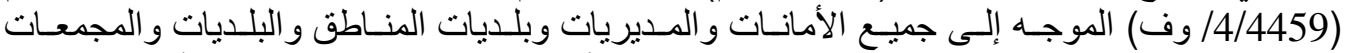

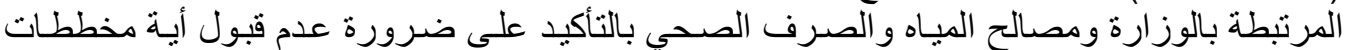

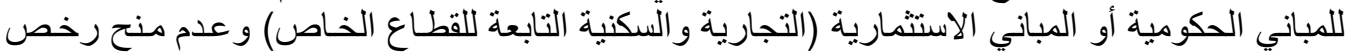

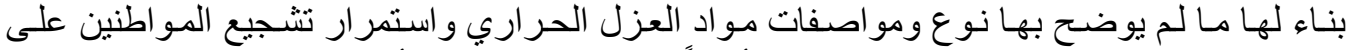

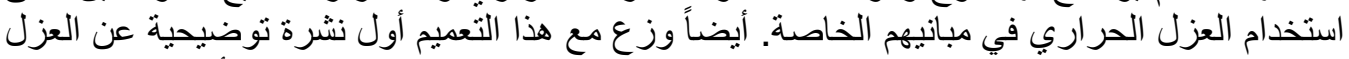

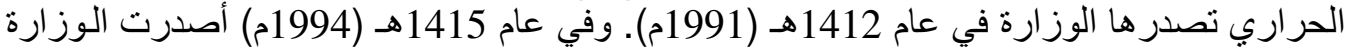

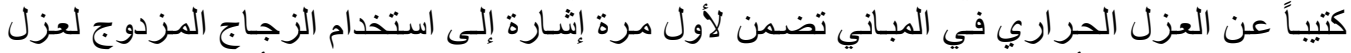

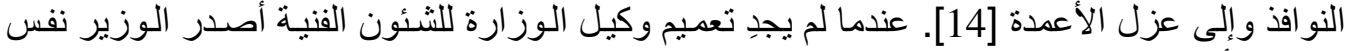

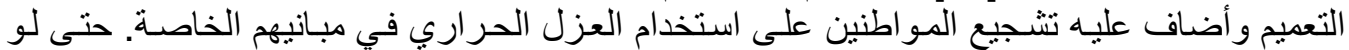

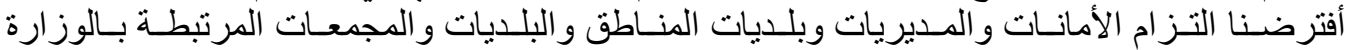

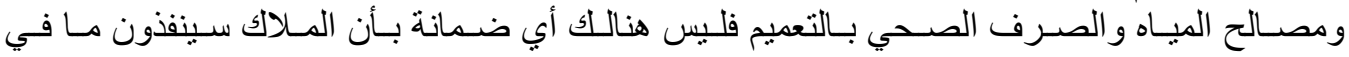




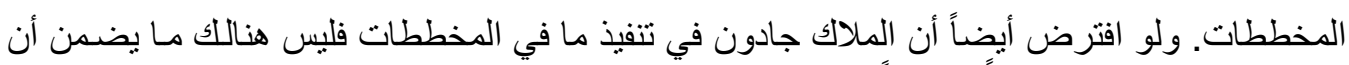

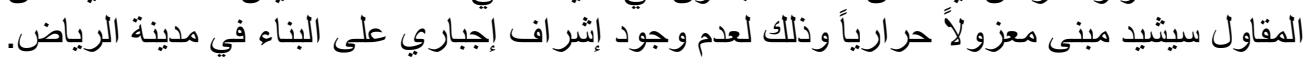

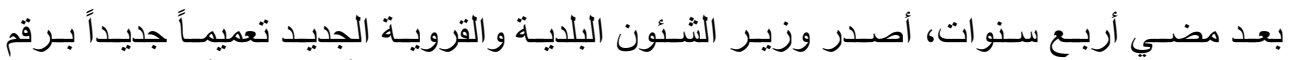

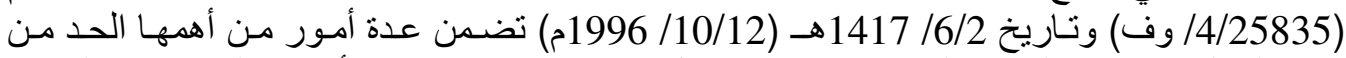

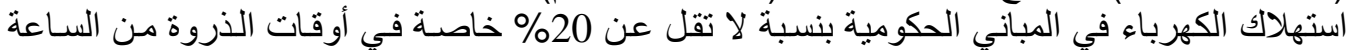

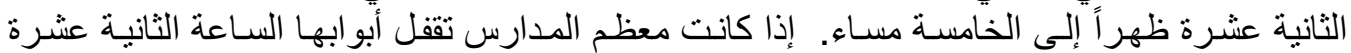

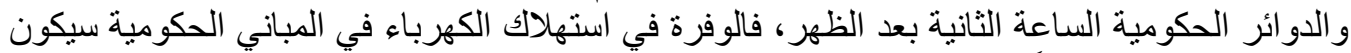

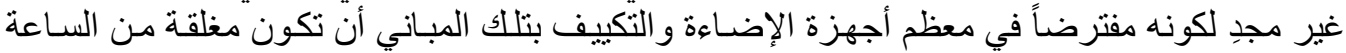

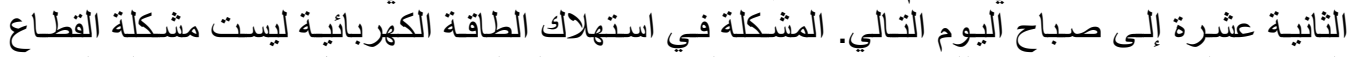

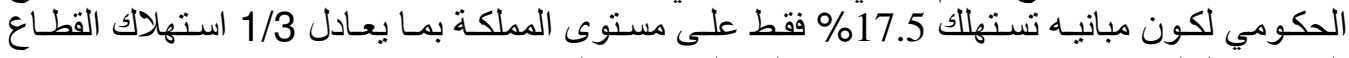
الخاص و البالغ (55.2\%) باستثناء ما تستهلكه الزر اعة و الصناعة (16.3\%) [15].

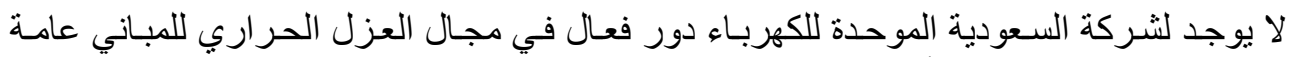

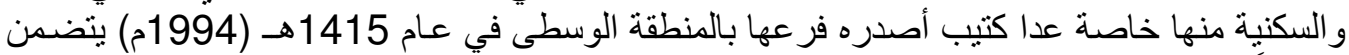

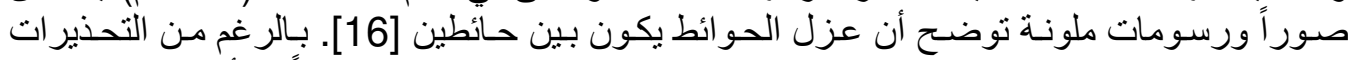

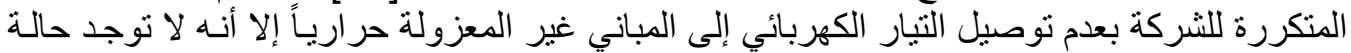

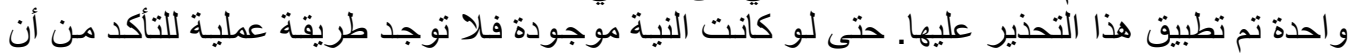

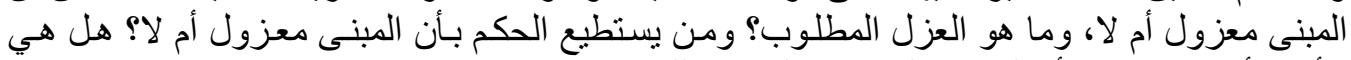

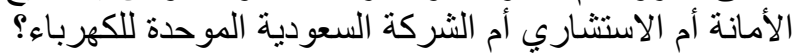

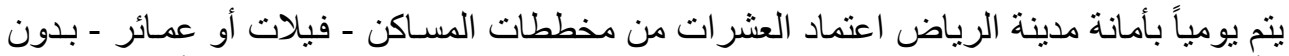

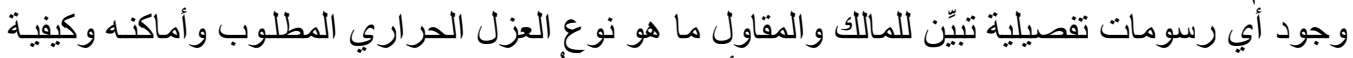

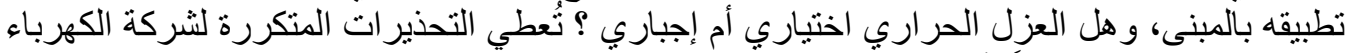

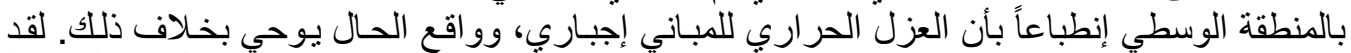

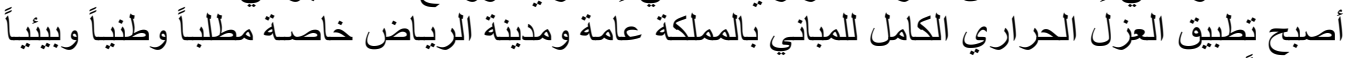
و إنسانيا.

\section{عينة الدراسة}

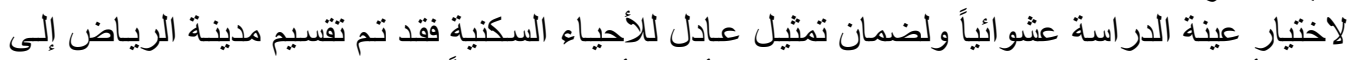

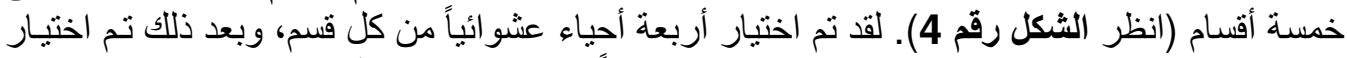

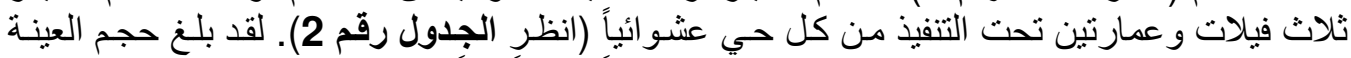

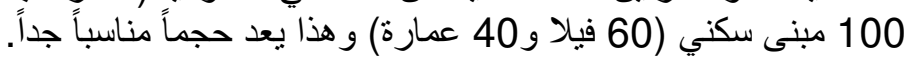

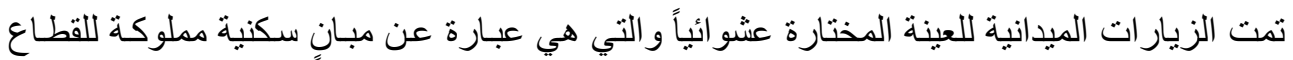

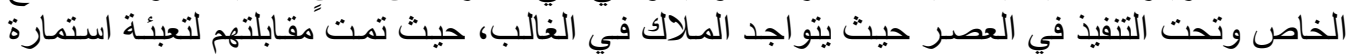

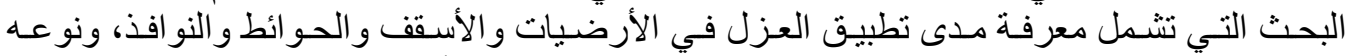

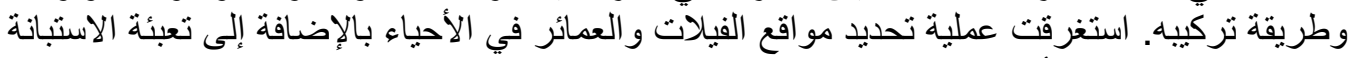

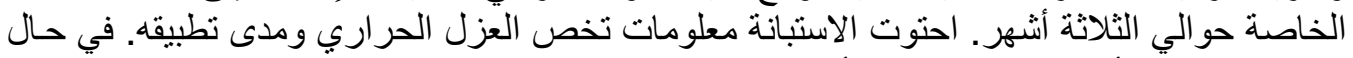

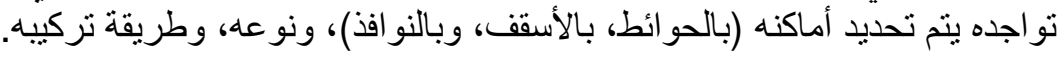
تحليل الوضع الراهن

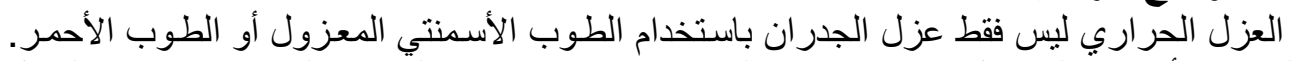

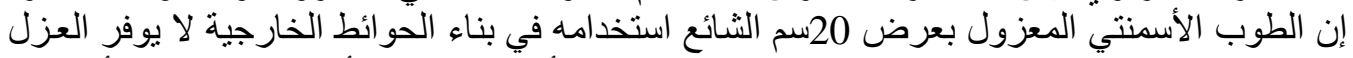

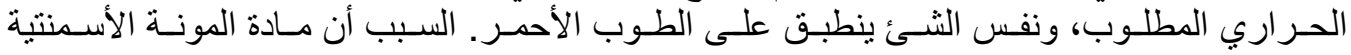




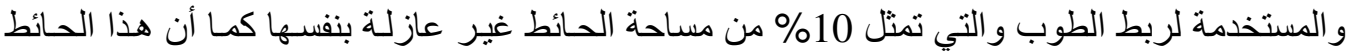

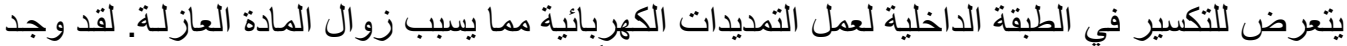

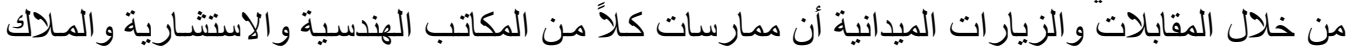

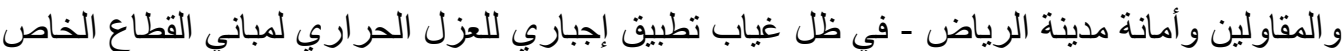
ـ تمثل عائقاً رئيساً أمام تطبيقة العياض العزل الحر اري الكامل.

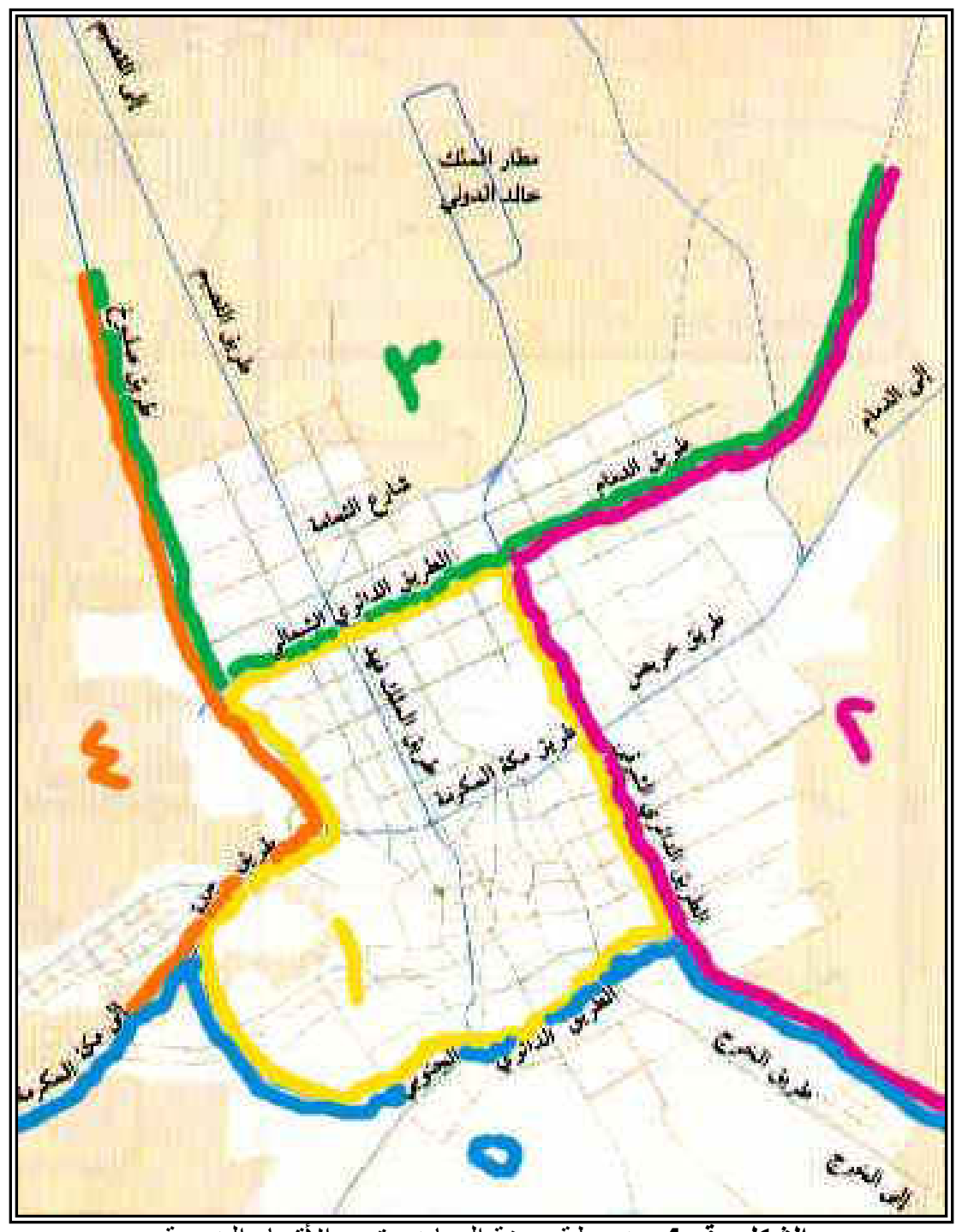

الشكل رقُم 4: خريطة مدينة الرياض تبين الأقسام الخمسة. 
الجدول رقم 2: يوضح أقسام مدينة الرياض وأسماء الأحياء و عدد المباني المختارة عشو ائياً.

\begin{tabular}{|c|c|c|c|c|c|}
\hline 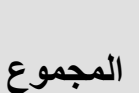 & العمائر & الفيلات & الأحياء المختارة عشوائياً | & أسم القسم & التسلسل \\
\hline 20 & 8 & $\overline{12}$ & البطحاء، الملز، النخيل، & الأحياء بداخل الطريق & $\overline{\overline{1}}$ \\
\hline 20 & 8 & 12 & السلام، الروضة، القدس، & وخارج الطريق الدائري. & 2 \\
\hline 20 & 8 & 12 & العقيق، الصحافة، الفلاح، & وخارج الطريق الدائري. & 3 \\
\hline 20 & 8 & 12 & طويق، العريجا، الهذى، & وخارج الطريقاء غرب الدائرياض*. & 4 \\
\hline 20 & 8 & 12 & بدر، الفوازية الثفاء، & وخارج الطريق الدائري. & 5 \\
\hline 100 & 40 & 60 & \multicolumn{3}{|c|}{ المجموع } \\
\hline
\end{tabular}

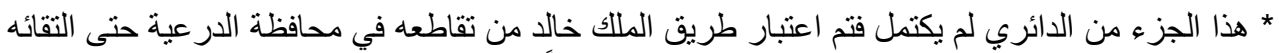
بطريق مكة ومن ثم وصوله إلى جسر وادي لبن المبل المعلق جزءاً من الطريق الدائري.

\section{أولاً: المكاتب الهندسية والاستشارية}

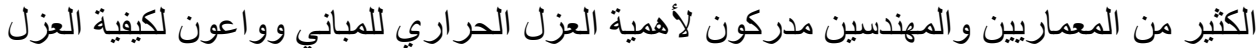

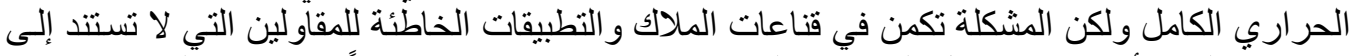

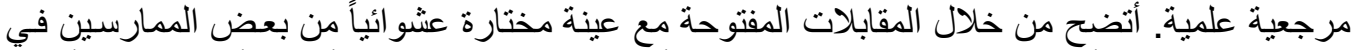

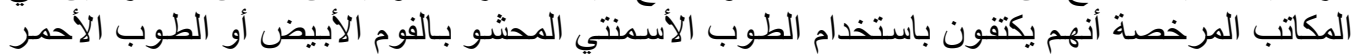

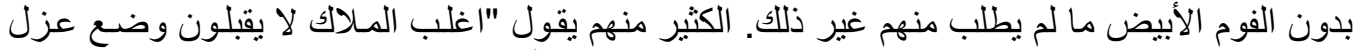

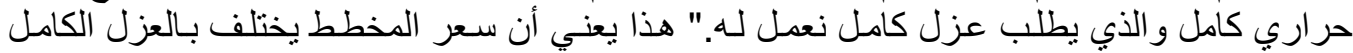

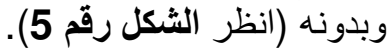

إن حماية الزبون من نفسه ومن المقاول بالإضـافة إلى الإخلاص في العمل مبل مبدآن من أهم مبادئ

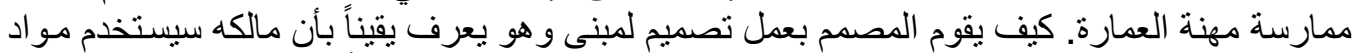

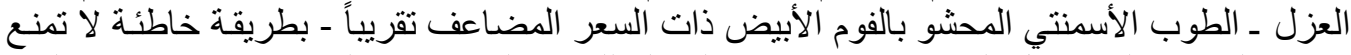

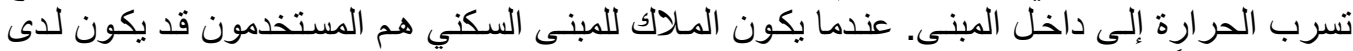

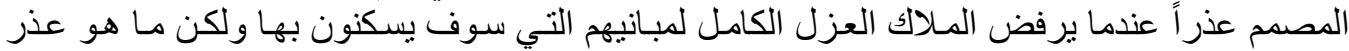
المصمم عندما يعلم بأن المستخدمين أناس آخرون؟ الكرال

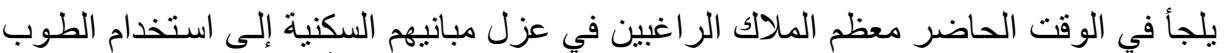

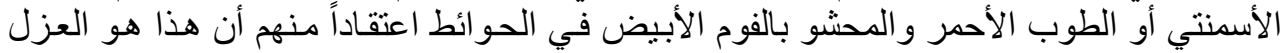

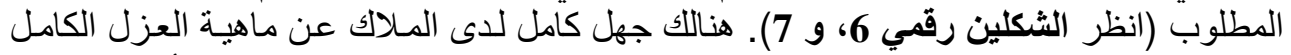

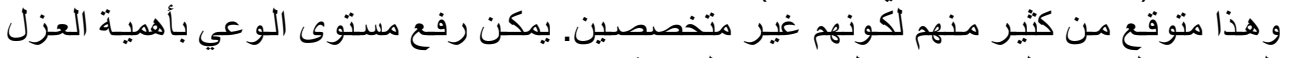
الحر اري الصحيح لديهم من خلال حملات التوعية. 


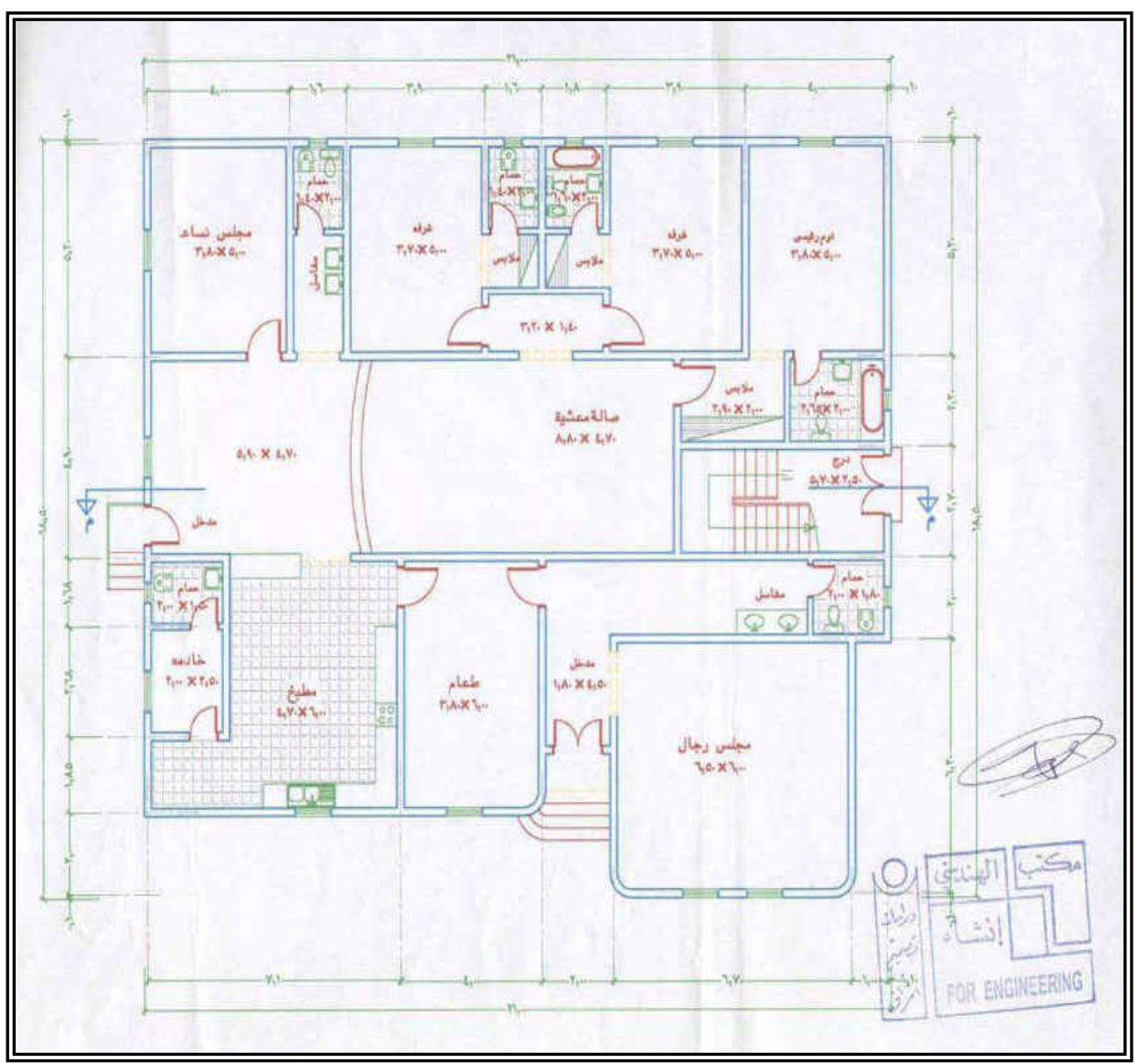

الشكل رقم 5: صورة مسقط أفقي للاور الأرضي لإحدى الفلل معتمد من المكتب وقسم الرخص بالأمانة بالرغم من عدم وضع المصدم للعزل الحر اري في الحوائط الخارجية. المصدر: أرشيف أمانة مدينة الرياض.

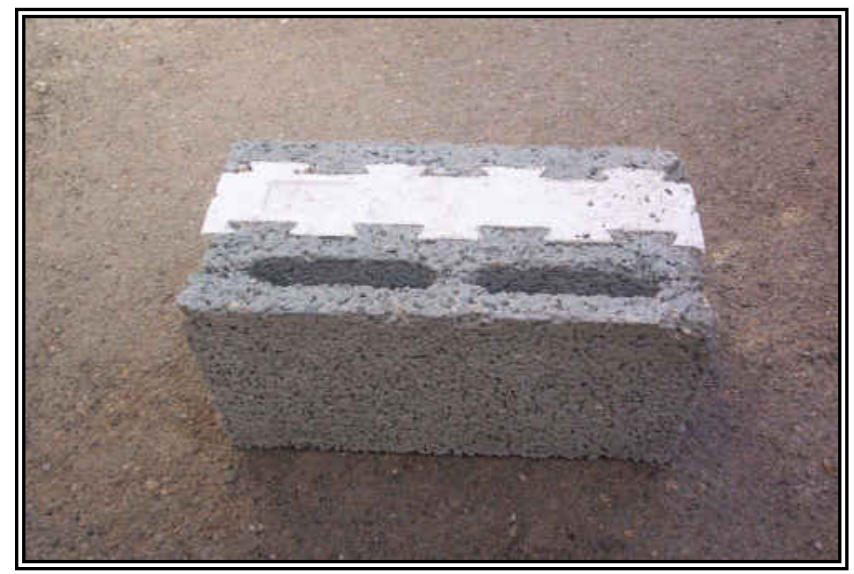

الشكل رقم 6: صورة لطوبة إسمنتية معزولة بالفوم بعرض 20سم تستخدم في بناء الحو ائط الخارجية. 


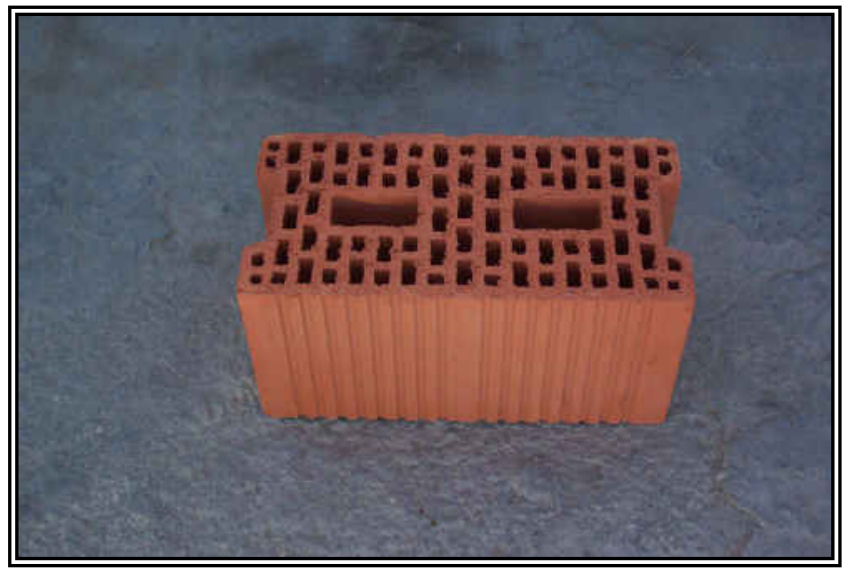

الشكل رقم 7: صورة لطوبة فخارية حمر اء بعرض 20سم تستخدم في بناء الحو ائط الخارجية ويمكن حشوها بالفوم الأبيض من خلاء بعرض الفتحتين الموجدتان في المنتصف.

ثالثاً: المقاولون

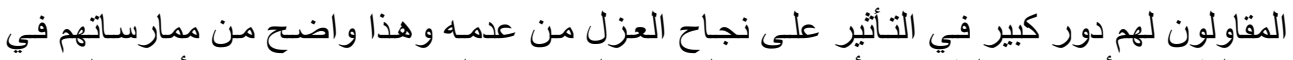

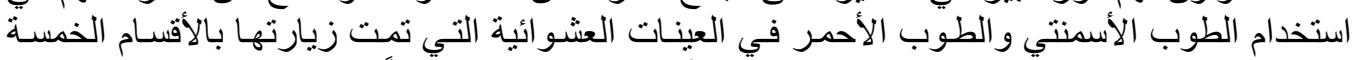

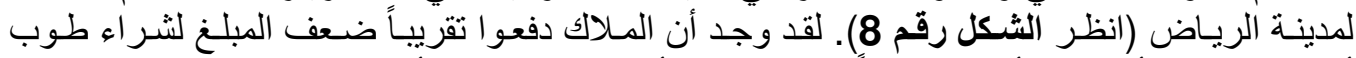

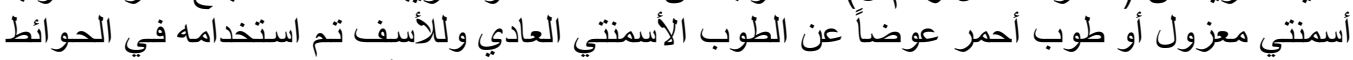

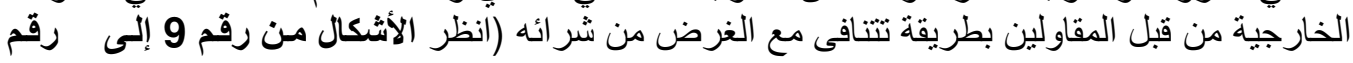

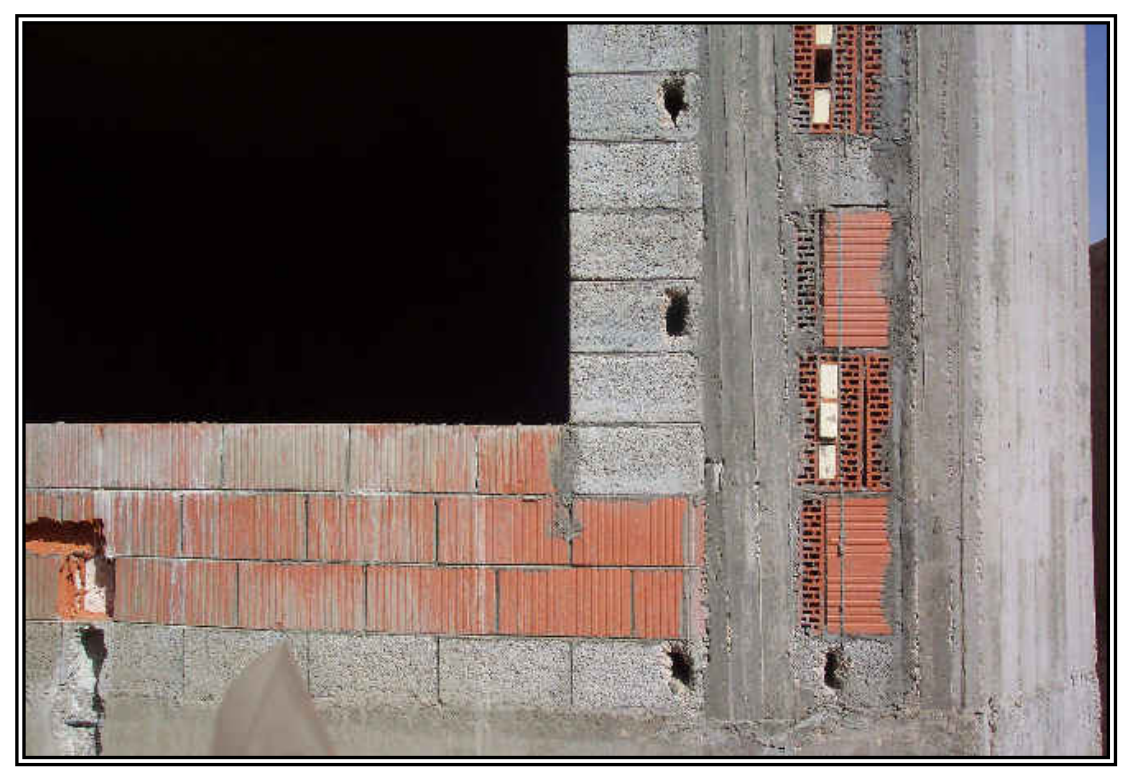

شكل رقم 8: صورة لحائط خارجي تبين الاستخدام الخاطي للطوب الأحمر من قبل المقاول. 


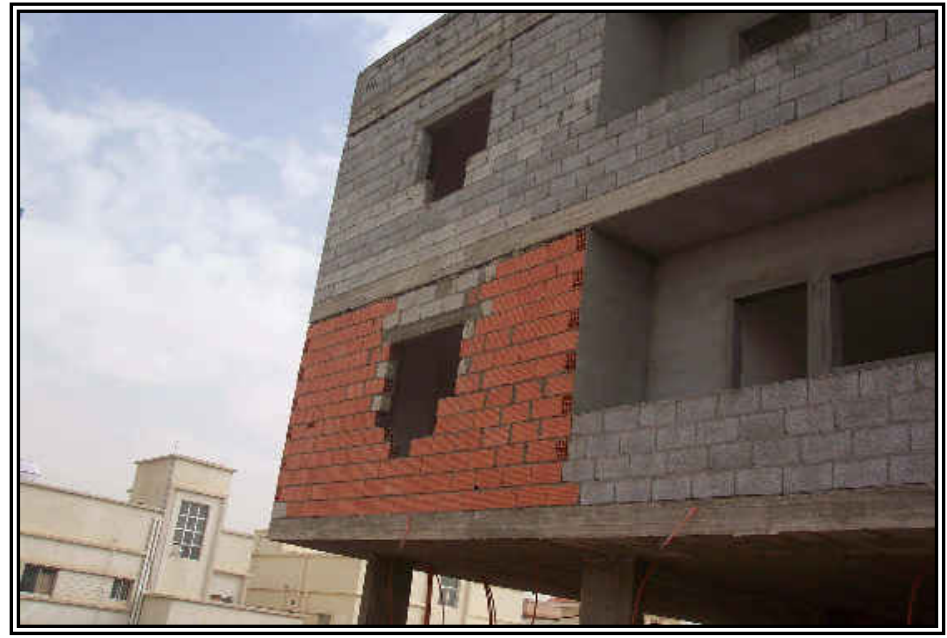

شكل رقم 9: استخدم المالك الطوب الأحمر في جزء من الدور الأول بينما استخدم الطوب الأسمنتي العادي بالدور الثاني.

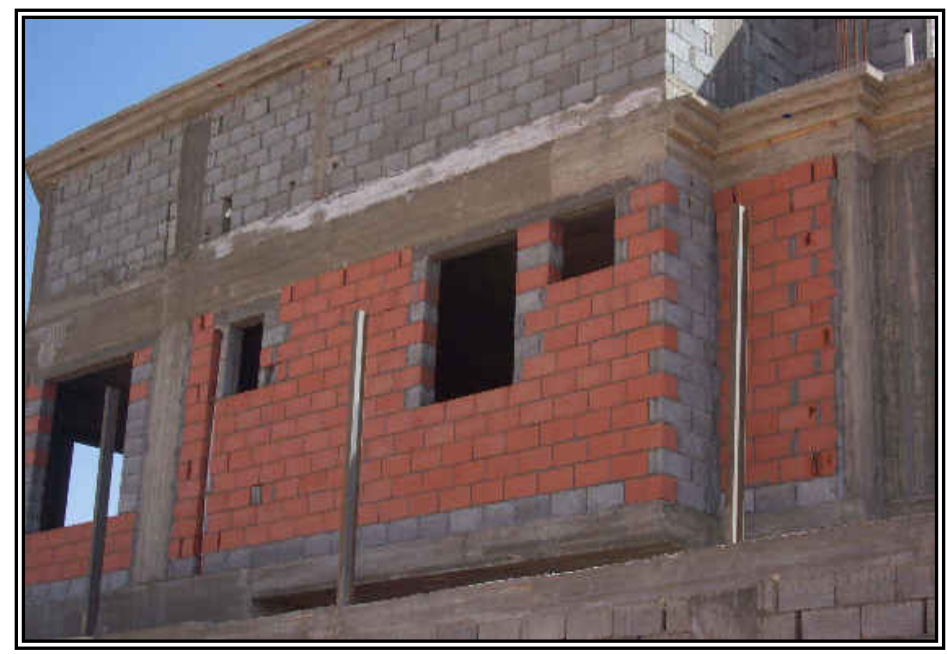

شكل رقم 10: صورة تبين استخدام الطوب الأحمر والطوب الأسمنتي العادي بطريقة غير سليمة من خلال

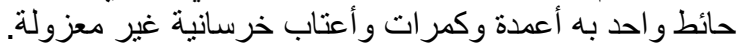

\section{رابعاً: أمانة مدينة الرياض}

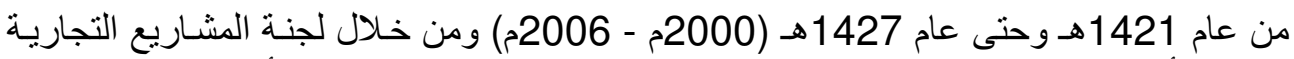

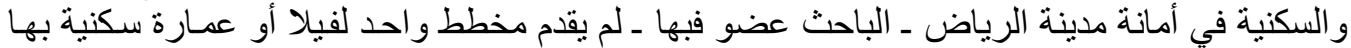

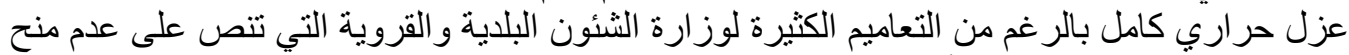

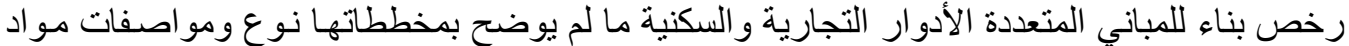

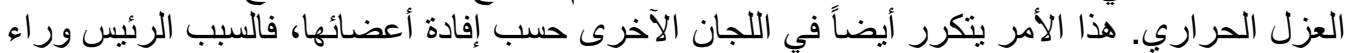

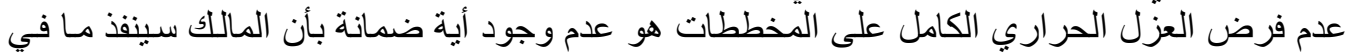


المخططات من عزل وخلافه. حتى لو كانت النية موجودة لاى المالك فلا يوجد أية ضمانة بأن المقاول

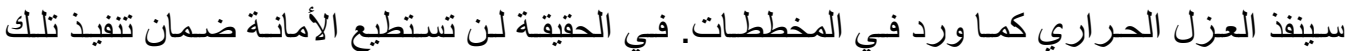

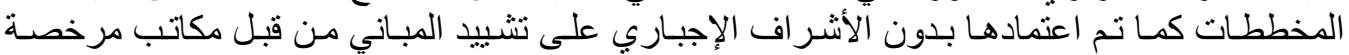

النتائج

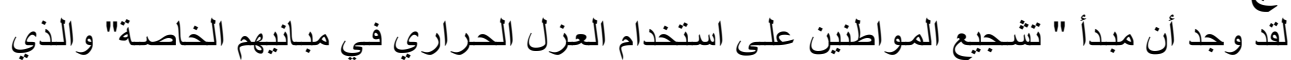

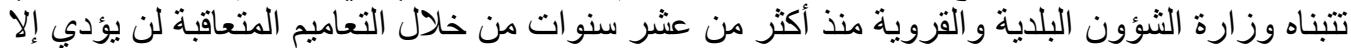
إلى استمر ار الوضع الحالي المتمنل في:

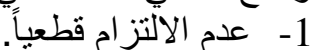
2- أو التطبيق الخاطئ الجزئي للعزل الحر ارئي. 3- أو التطبيق الصحيح الجزئي للعزل الحرل الحراري.

\section{أولاً: علام الالتزام قطعياً}

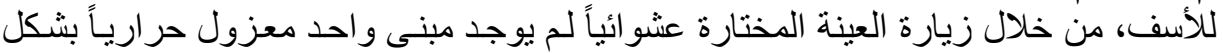

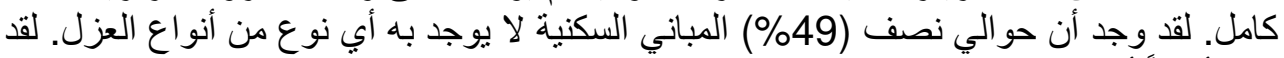

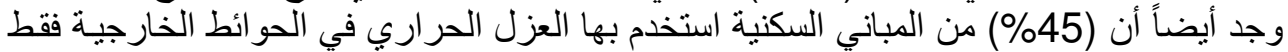

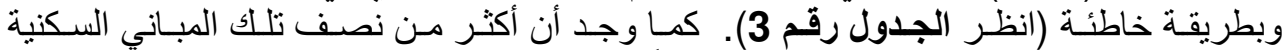

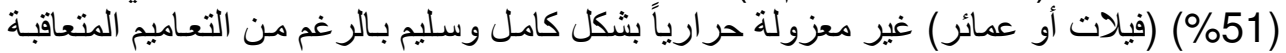

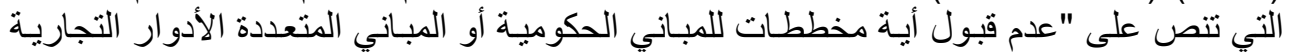

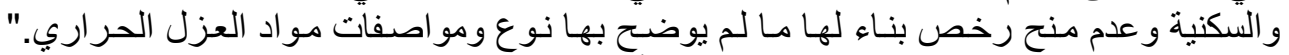

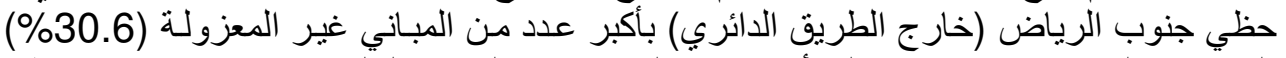

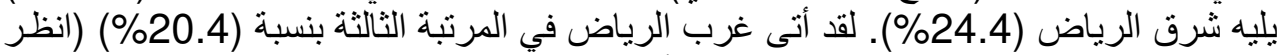
الجدول رقم 4). حظي شمال ووسط الرياض بأقل عدد من المباني غير المعزولة (12.3\%).

الجدول رقم 3: الوضع الر اهن لاستخدام العزل الحراري بالمباني السكنية المنفةة بمدينة بالرياض.

\begin{tabular}{|c|c|c|c|c|c|}
\hline ملاحظات & المجموع & 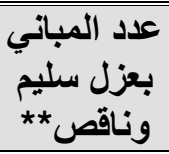 & بعزل غليز & بدون عزاني & 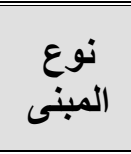 \\
\hline الأعمدة والكمرات والأعتاب & 60 & 6 & 27 & 27 & فَيلا \\
\hline الأعمدة والكمرات والأعتاب غير معزولة. & 40 & - & 18 & 22 & عمارة \\
\hline & 100 & 6 & 45 & 49 & المجموع \\
\hline & $\% 100$ & $\% 6$ & \%45 & $\% 49$ & النسبة \\
\hline
\end{tabular}

* العزل المستخدم حائط من الطوب الأسمنتي محشو بالفوم أو الطوب الأحمر.

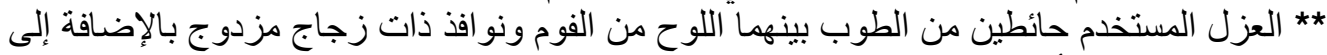
السقف المعزول بألو اح من الفوم. المن الطوب 
الجدول رقم 4: توزيع المباني السكنية بدون عزل بمدينة الرياض.

\begin{tabular}{|c|c|c|c|c|c|c|}
\hline \multirow[b]{2}{*}{ المجموع } & \multicolumn{5}{|c|}{ الموقع من المدينة } & \multirow[b]{2}{*}{ وع المبنى } \\
\hline & الجنوب & الغرب & الشمال & الثرق & الوسط & \\
\hline 27 & 9 & 6 & 6 & 6 & - & فيلا \\
\hline 22 & 6 & 4 & - & 6 & 6 & عمارة \\
\hline 49 & 15 & 10 & 6 & 12 & 6 & المجموع \\
\hline$\% 100$ & $\% 30.6$ & $\% 20.4$ & $\% 12.3$ & $\% 24.4$ & $\% 12.3$ & النسبة \\
\hline
\end{tabular}

ثانياً: التطبيق الجزئي الخاطئ للعزل الحراري

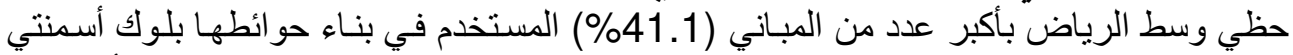

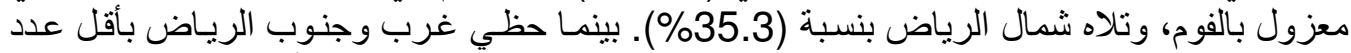

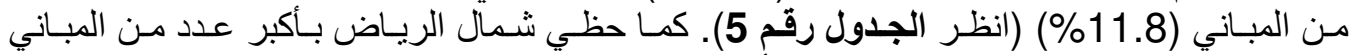

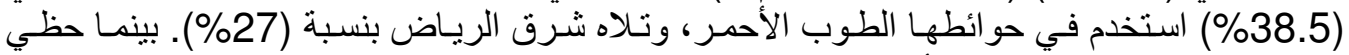
وسطو غرب وجنوب الرياض بأقل عدد من المباني (11.5\%) (انظر الجدول رقم 6).

الجدول رقم 5: استخدام الطوب الأسنتي الدشو بالفوم لعزل الحوائط الخارجية.

\begin{tabular}{|c|c|c|c|c|c|c|}
\hline \multirow[b]{2}{*}{ المجموع } & \multicolumn{5}{|c|}{ الموقع من المدينة } & \multirow[b]{2}{*}{ نوع المبنى } \\
\hline & الجنوب & الغزب & الثمال & الثرق & الوسط & \\
\hline 9 & - & - & 6 & - & 3 & فيلا \\
\hline 8 & 2 & 2 & - & - & 4 & عمارة \\
\hline 17 & 2 & 2 & 6 & - & 7 & المجموع \\
\hline$\% 100$ & $\% 11.8$ & $\% 11.8$ & $\% 35.3$ & - & $\% 41.1$ & النسبة \\
\hline
\end{tabular}

الجدول رقم 6: استخدام الطوب الأحمر لعزل الحو ائط الخارجية.

\begin{tabular}{|c|c|c|c|c|c|c|}
\hline \multirow[b]{2}{*}{ المجموع } & \multicolumn{5}{|c|}{ الموقع من المدينة } & \multirow[b]{2}{*}{ نوع المبنى } \\
\hline & الجنوب & الغرب & الشمال & الشرق & الوسط & \\
\hline 18 & 3 & 3 & 6 & 3 & 3 & فيلا \\
\hline 8 & - & - & 4 & 4 & - & عمارة \\
\hline 26 & 3 & 3 & 10 & 7 & 3 & المجموع \\
\hline$\% 100$ & $\% 11.5$ & $\% 11.5$ & \%38.5 & $\% 27.0$ & $\% 11.5$ & النسبة \\
\hline
\end{tabular}




\section{ثالثاً: التطبيق الجزئي الصحيح للعزل الحراري}

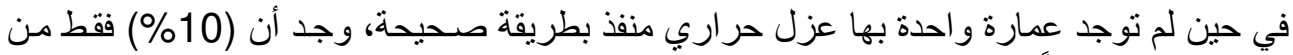
الفيلات معزولة حرارياً بطريقة صحيحة ولكن بشكل غير كامل (انظر الجداول من رقم 5 إلى إلى 7). لقد

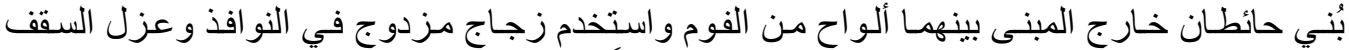

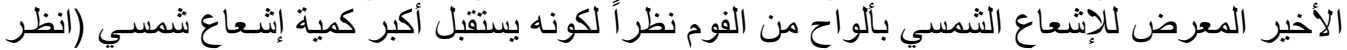

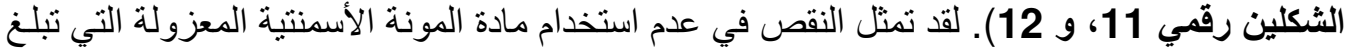

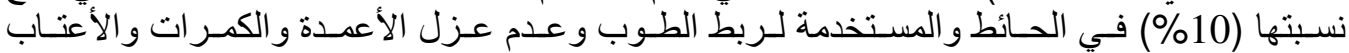

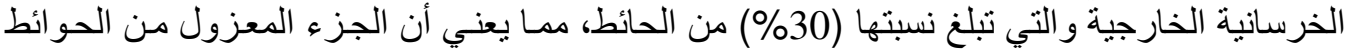

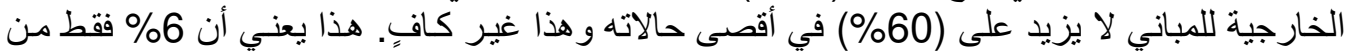
المباني السكنية في الرياض بها عزل حراري منفذ بطريقة صحيحة وغير كامل.

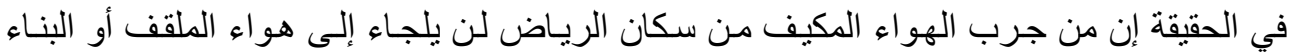

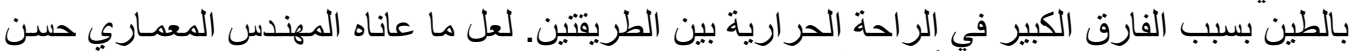

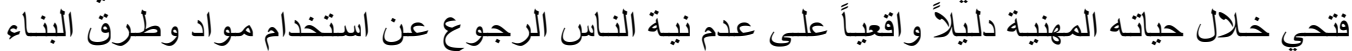
الحديثة بالإضافة إلى التقنية الحديثة للتكييف. لتحقيق مستوى الر احة الإنسانية لمستخدمي المبنى السكني

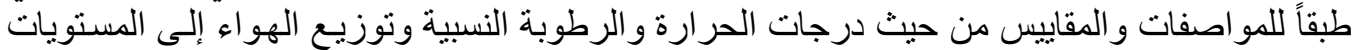
القياسية المريحة لا بد من عمل ما يلي [17]:

الحماية الايجابية لحو ائط وأسقف المسكن من أشعة الثمس المباثرة.

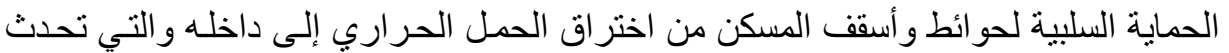

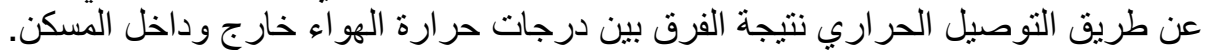

الجدول رقم 7: استخدام العازل في الحائط و النافذة والسقف الأخير.

\begin{tabular}{|c|c|c|c|c|c|c|c|c|c|}
\hline \multirow[b]{2}{*}{$\%$} & \multirow{2}{*}{ المساكن } & \multirow{2}{*}{ المجموع } & \multicolumn{5}{|c|}{ الموقع من المدينة } & \multirow{2}{*}{\multicolumn{2}{|c|}{ نوع المبنى }} \\
\hline & & & الجنوب & الغرب & الشمال & الشرق & الوسط & & \\
\hline$\% 10$ & 60 & 6 & - & - & - & 3 & 3 & حائط & \multirow{2}{*}{ - } \\
\hline$\% 10$ & 60 & 6 & - & - & - & 3 & 3 & نافذة & \\
\hline$\% 10$ & 60 & 6 & - & - & - & 3 & 3 & سقف & $\lambda$ \\
\hline - & 40 & - & - & - & - & - & - & حائط & y \\
\hline - & 40 & - & - & - & - & - & - & نافذة & 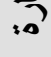 \\
\hline - & 40 & - & - & - & - & - & - & سقف & \\
\hline$\% 6$ & 100 & 6 & - & - & - & 3 & 3 & $\varepsilon$ & الم \\
\hline
\end{tabular}




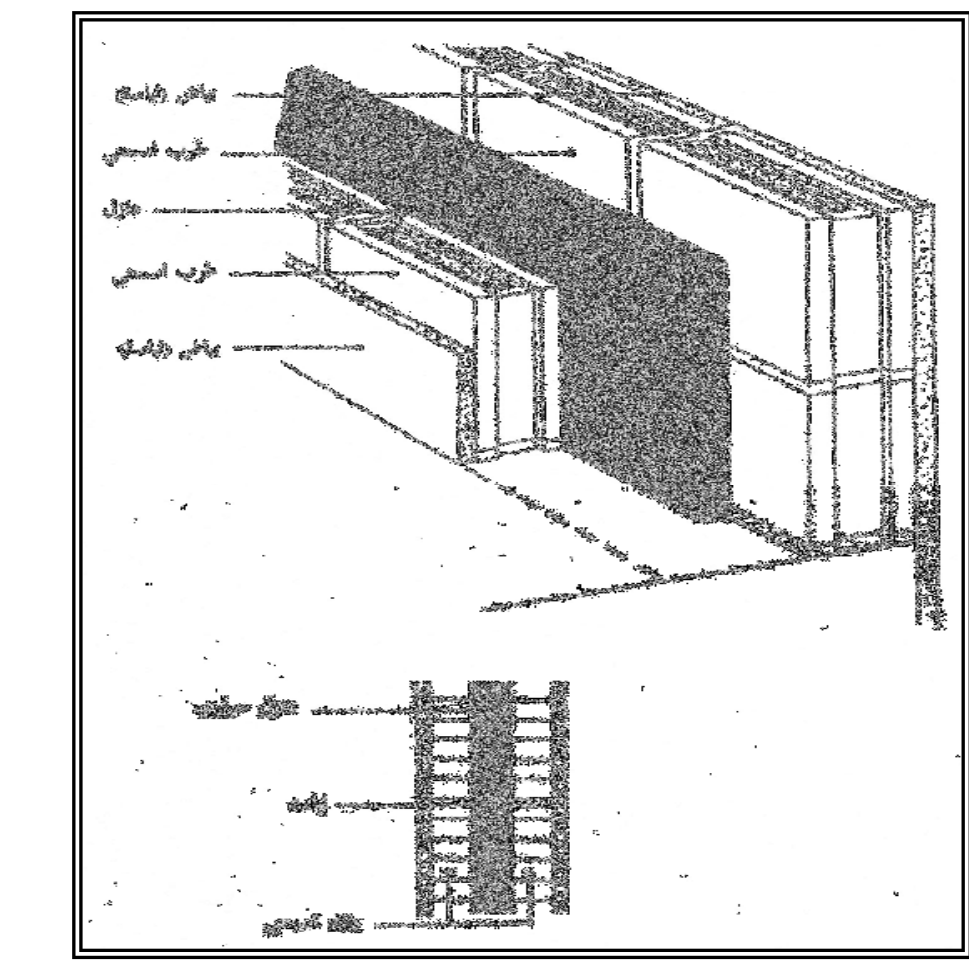

شكل رقم 11: قطاع في حائط معزول (المرجع: الثركة السعودية الموحدة للكهرباء).

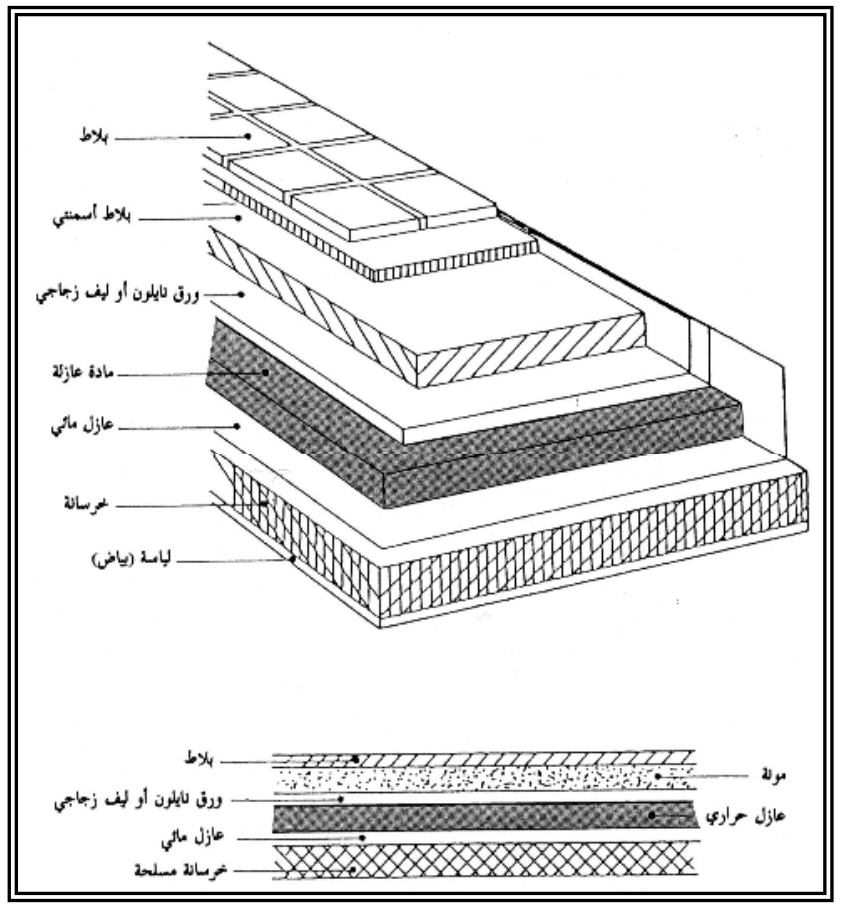

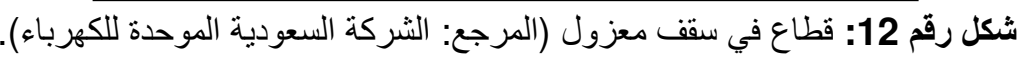




\section{الخاتمة والتوصيات}

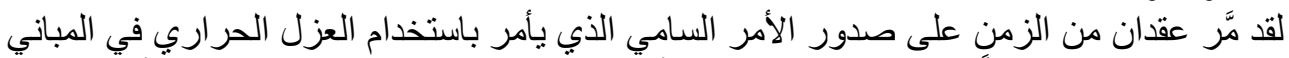

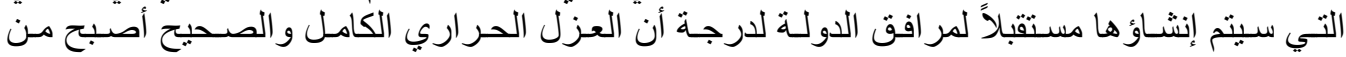

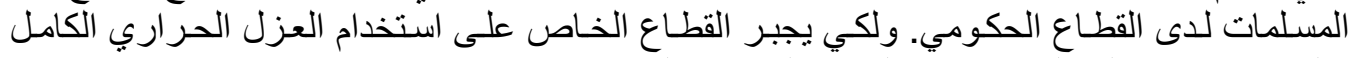
والصحيح يجب على الجهات ذات العلاقة القيام بما يلي: الئي:

\section{صندوق التنمية العقارية}

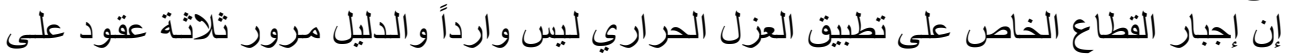

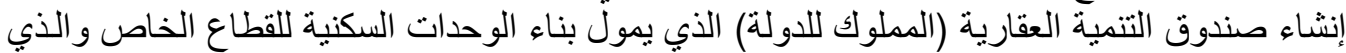

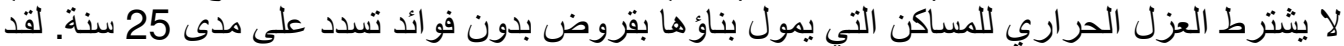

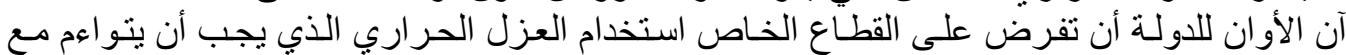

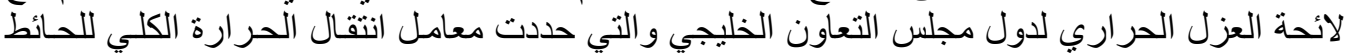

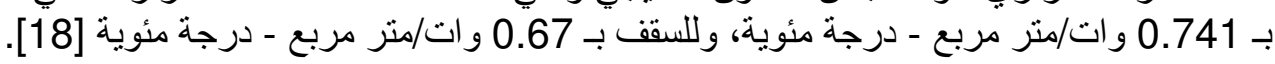

\section{الثركة السعودية الموحدة للكهرباء}

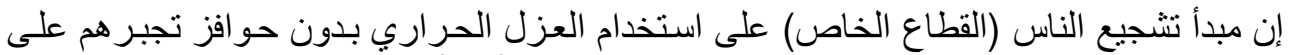

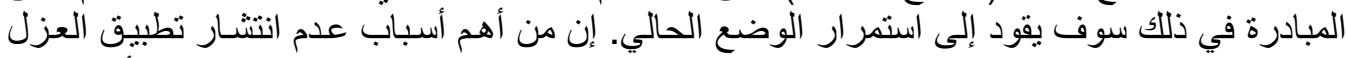

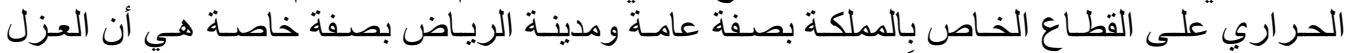

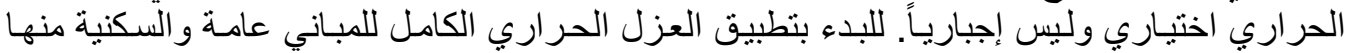

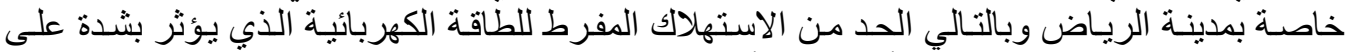

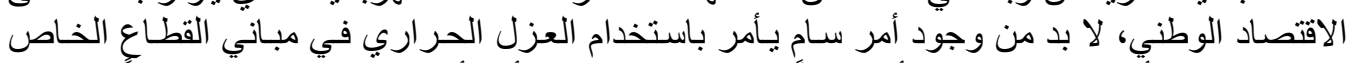

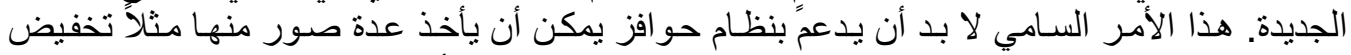

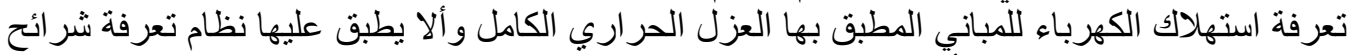

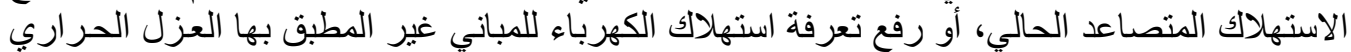

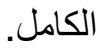

\section{وزارة الثؤون البلاية والقروية}

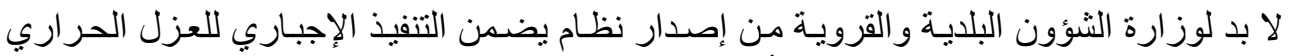

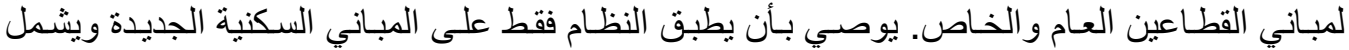

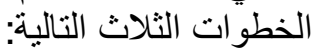

1- عدم اعتماد أي مخطط لأي مبنى سكني لا يتوفر بـه العزل الحراري لكامل أجزاء الغلاف

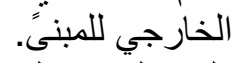

2- إلزام المكتب المصمم بتقيم ما يفيد بقيام الماللك بتتفيذ ما في المخططات المعتمدة بما في ذلك

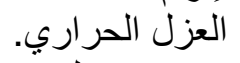

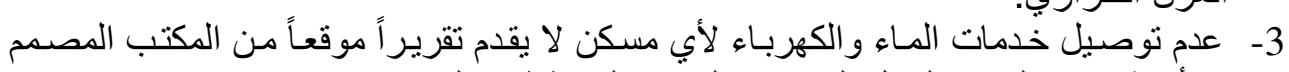

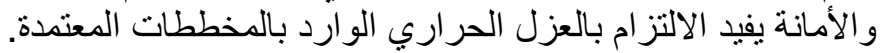

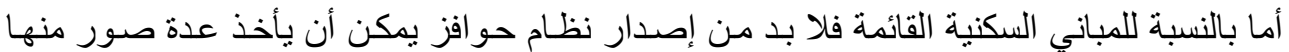

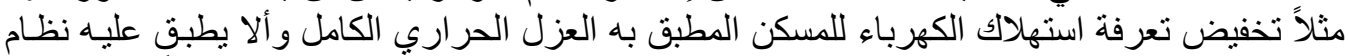

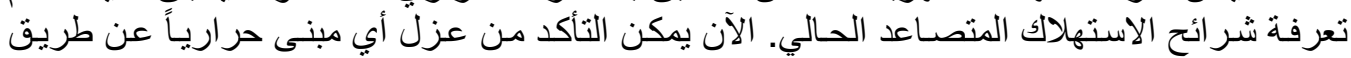

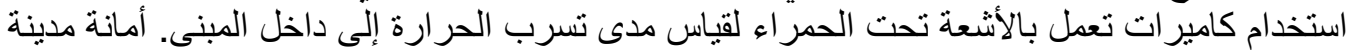

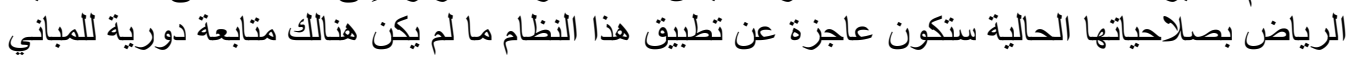


بالمدينة من خلال البدء بإصدار "شهادة الإشغال للمباني" للتأكد من وجود العزل الحراري لكامل أجزاء الغلاف الخارجي للمباني الحديثة والقائمة.

إن الحل الوحيد للاستهلاك المفرط للطاقة الكهربائية الذي يؤُشِّ بشدة على الاقتصـاد الوطني هو العزل الحر اري الكامل و المنظم و المقنن لمبانينا و المتمثل فيما يليّي:

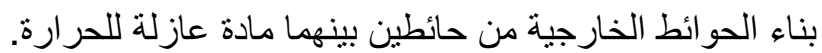

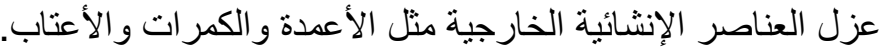

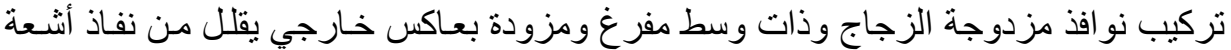

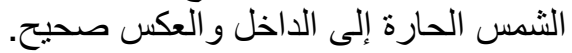
تركيب إطار النافذة في مكان يحول دون تسرب الإب الحرب ارة إلى إلى الداخل.

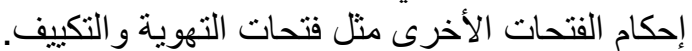
استخدام أبو اب خارجية مزدوجة عبارة عن بابين بينهم مسافة لا تقل عن الإن 2.00م لحجز الهواء الخارجي الحار من الاخول إلى الداخل. عزل السقف الأخير بمادة عازلة للحر الخدارة

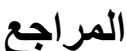

فتحي، حسن. "عمارة الفقراء." الجامعـة الأمريكية بالقاهرة، القاهرة، جمهوريـة مصر العربيـة،

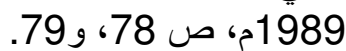

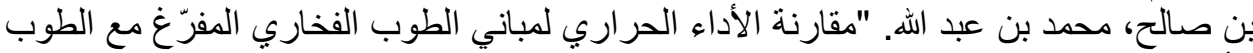

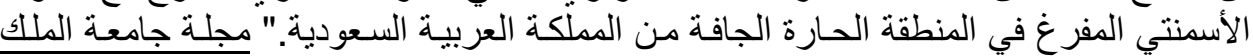

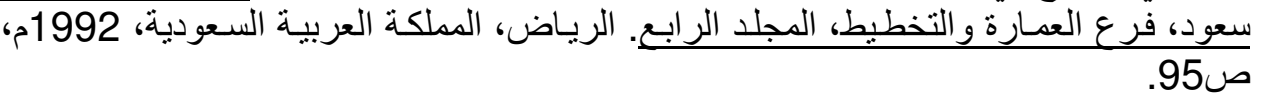
المقرن، خالد بن عبد الله. "مدخل لترشيد استهلاك المباني للطاقة الكهربائية في مدينـة الرياض. الرياض."

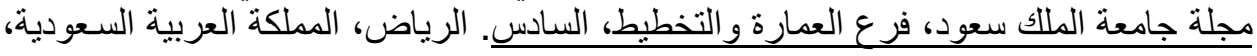

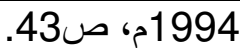

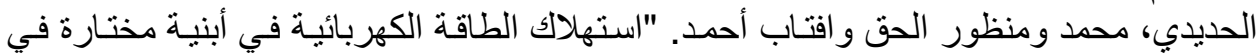

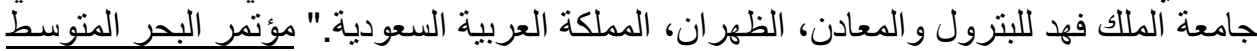

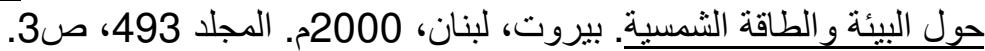

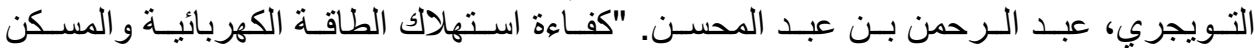

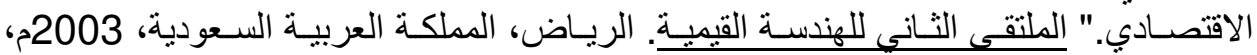

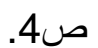

[6] Close, Paul Dunham." Sound Control and Thermal Insulation of Buildings." Reinhold Publishing Corporation, New York, U. S. A. 1977, p473.

[7] Lea, F. M.," The Insulation of Buildings." Multi Machine Plates Limited, London, U. K., 1955, pv.

[8] The U. S. Department of Energy," Economic Thickness for Industrial Insulation," The Fairmont Press Inc., Atlanta, GA, U. S. A., 1983, p1. 


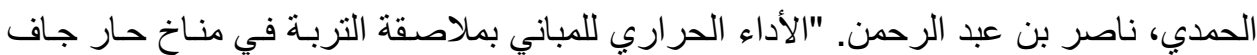

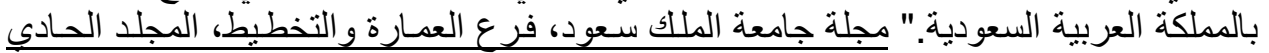

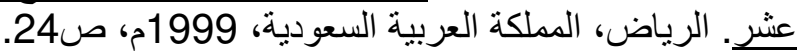

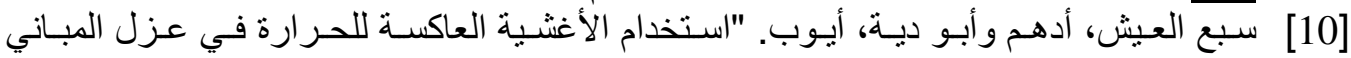

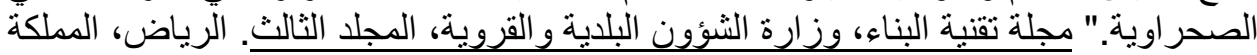

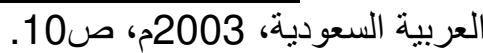

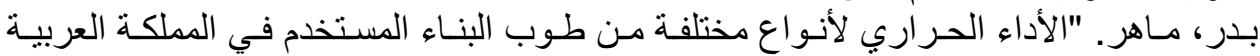

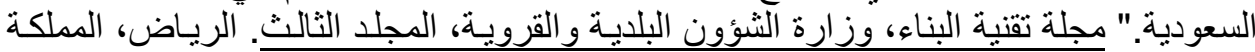

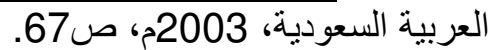

[12] Szokolay, S. V. " Environmental Science Handbook for Architects and Builders. " The Construction Press, Lancaster, London, New York, 1980, p418.

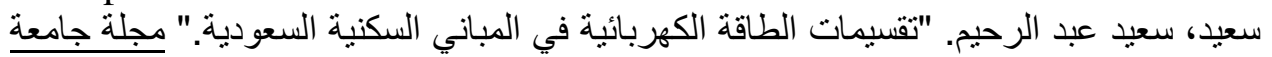

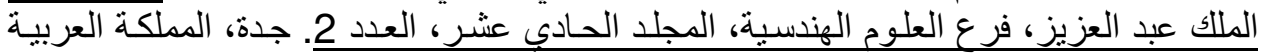

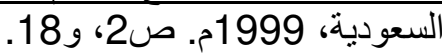

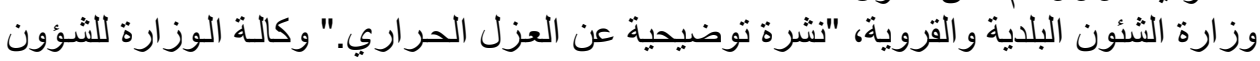

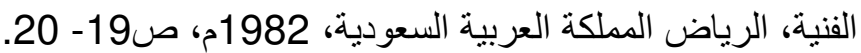

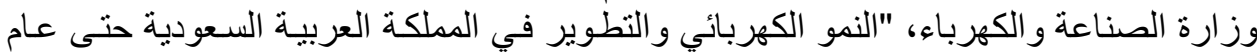

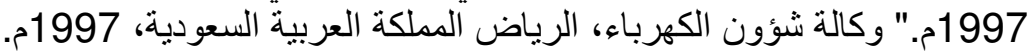

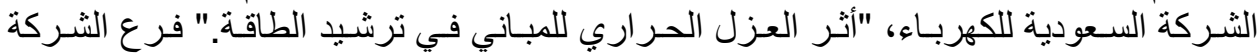

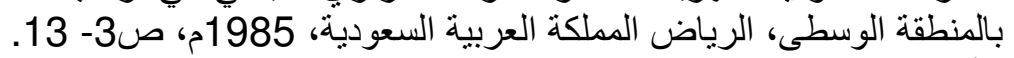

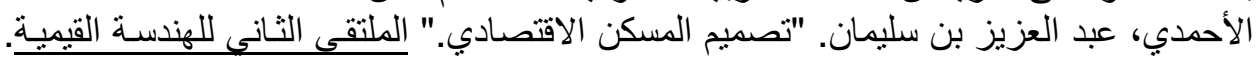

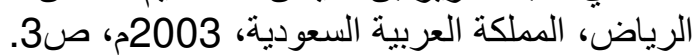

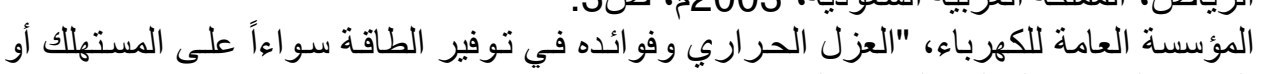

